\title{
Field scale functional agrobiodiversity in organic wheat: Effects on weed reduction, disease susceptibility and yield
}

\author{
Ambrogio Costanzo *,1, Paolo Bàrberi \\ Institute of Life Science, Scuola Superiore Sant'Anna, Piazza Martiri della Libertà 33, 56127 Pisa (Italy)
}

\section{A R T I C L E I N F O}

\section{Article history:}

Received 9 November 2015

Received in revised form 22 January 2016

Accepted 25 January 2016

\section{Keywords:}

Composite Cross Population

Genetic diversity

Living mulch

Subterranean clover

Weed suppression

Wheat

\begin{abstract}
A B S T R A C T
Deployment of diversity at the species and at the genetic levels can improve the ability of crops to withstand a wide range of biotic and abiotic stressors in organic and low-input cropping systems, where the response to stresses through external input is limited or restricted in comparison with conventional systems. Although there are several strategies to use agrobiodiversity in wheat-based systems, their implementation is limited by the lack of a clear relationship between agrobiodiversity and provision of key agroecosystem services. In a three-year field trial in Central Italy we compared common wheat Italian and Hungarian pure lines, Italian old cultivars and Hungarian and British Composite Cross Populations (CCPs), grown with or without a contemporarily sown Subterranean clover living mulch. We aimed at linking crop performance, in terms of yield, weed reduction and disease susceptibility, to three categories of functional diversity: (1) functional identity, represented by the identifying traits of cultivars, (2) functional diversity, represented by the genetic heterogeneity of wheat crop population, and (3) functional composition, represented by the co-presence of wheat and the living mulch.

Concerning cultivars, effects of functional identity were predominant for weed reduction and grain yield. Old cultivars tended to better suppress weeds but to be less yielding. Italian cultivars were more advantaged than cultivars of foreign origin, thanks to a better matching of their growth cycle into local climate. Functional diversity effects on yield and weed reduction were confounded with identity effects, given that all the CCPs were of foreign origin. In fact, the performance of CCPs was generally aligned with a central-European pure line. However, differences in yield components suggest that CCPs can evolve peculiar yield formation strategies. Moreover, CCPs were less susceptible than pure lines to foliar diseases. For functional composition, the living mulch was able to reduce dicotyledonous weed abundance and weed biomass without reducing wheat yield unless wheat was poorly established. Despite the strong morphological and phenological differences among the tested cultivars, no interactions were found between cultivar and living mulch presence, suggesting that, in conditions similar to our experiments, there is room to freely combine elements of crop diversity. Crop diversification strategies in wheat should be further explored and optimized, especially by constituting CCPs from locally adapted germplasms and by improving the feasibility and efficacy of legume living mulches.
\end{abstract}

(C) 2016 Elsevier B.V. All rights reserved.

\section{Introduction}

Common wheat (Triticum aestivum L.) and durum wheat (Triticum durum Desf.) are the leading crops for human nutrition in Europe and in most temperate regions worldwide, and as such, they are facing the challenge of being produced more sustainably, with reduced levels of external inputs. In this respect, wheat is the cereal crop with the largest acreage under organic management.

\footnotetext{
* Corresponding author.

E-mail address: ambrogio.c@organicresearchcentre.com (A. Costanzo).

1 Present address: Organic Research Centre, Hamstead Marshall, Newbury RG20 OHR (United Kingdom).
}

The most recent figures available show that in 2012 the total area grown worldwide with organic cereals totalled to 2,652,864 ha, of which wheat represented ca. 42\% (Willer and Lernoud, 2014).

Wheat production faces a wide range of constraints, notably weed competition, diseases, reduced nutrient availability and climate unpredictability. In organic and low-input systems the array of external inputs able to buffer these constraints is limited, which prevents farmers from obtaining high and stable yields. Several authors have been calling for a paradigm shift in wheat production, to facilitate the transition of wheat production from conventional to organic and low-input cropping systems (Wolfe et al., 2008).

Adaptation of wheat crops to organic and low-input cropping systems - these latter intended, in the context of our paper, as cropping systems managed with little or no use of external inputs, 

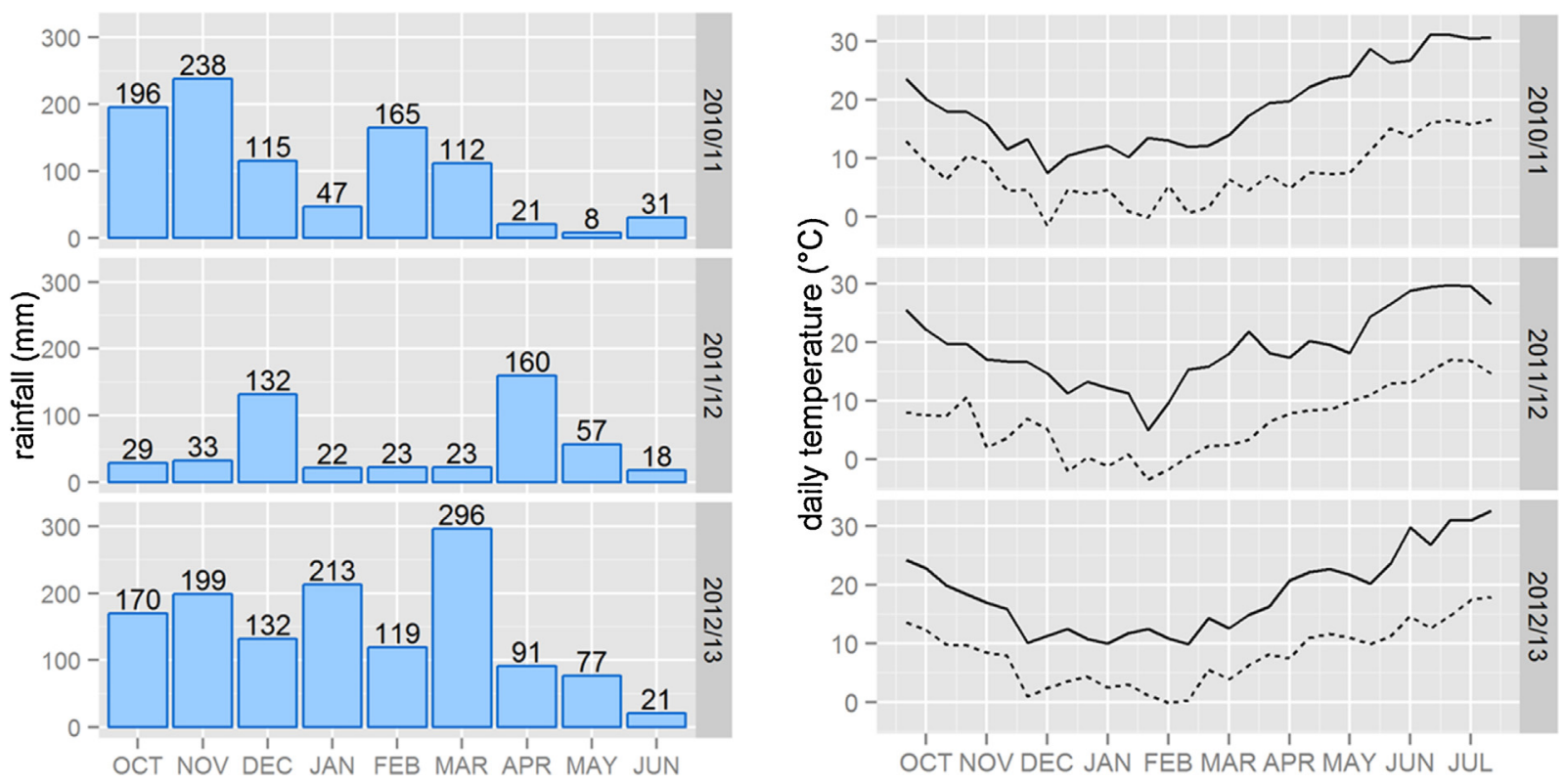

Fig. 1. Monthly rainfall (left) and maximum (-) and minimum (- - -) daily temperature (right) during the three growing seasons.
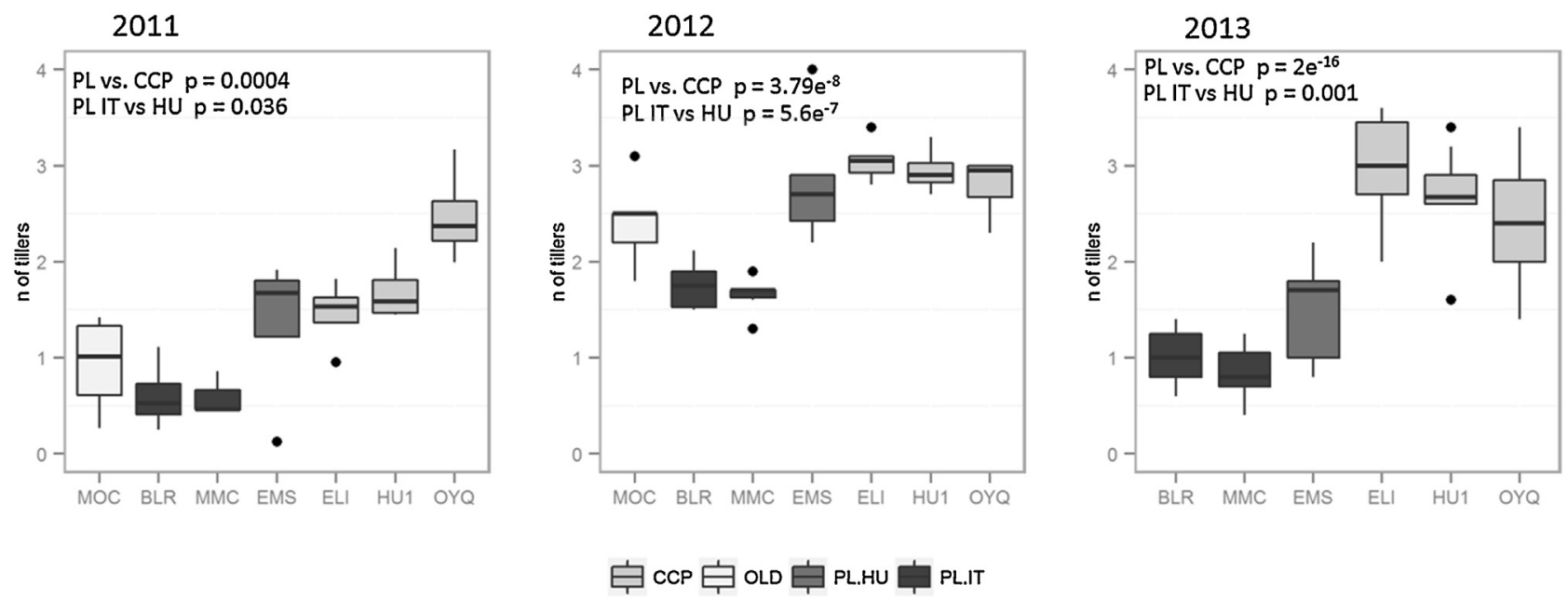

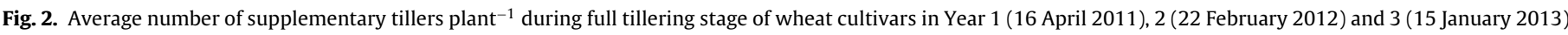
of Trial \#1. P-values of orthogonal linear contrasts are indicated.

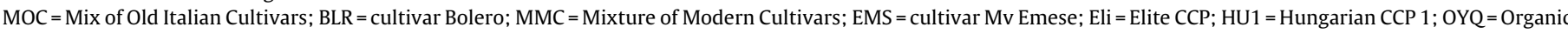
Yield-Quality CCP. 'OLD vs MOD' = Old vs. Modern cultivars; 'PL vs CCP' = Pure Lines vs CCP; 'PL IT vs HU' = Pure Lines Italian vs Hungarian Cultivars.

including these managed by resource-poor farmers (Ceccarelli, 1996) - and to local agro-climatic conditions at a finer scale (Ceccarelli, 1989) have generally emerged as the main targets of novel wheat breeding approaches. As a result, Value for Cultivation and Use (VCU) testing protocols and breeding programmes dedicated to organic farming are now available (Foletto, 2008; Jones et al., 2003). Further, more interest on old wheat cultivars is reemerging (Mason and Spaner, 2006; Stagnari et al., 2013).

Diversification of the crop stand is part of the overall strategy to improved wheat performance in organic and low-input systems, based on the potential of diversity to deliver agroecosystem services (Newton et al., 2009). Regarding diversification at the genetic level, there is a vast literature on cultivar mixtures (Kiær et al., 2009; Mundt et al., 1995, 1994; Wolfe, 2000) and there is an increased attention on new types of cultivars characterized by high genetic diversity (Wolfe et al., 2008). The most important example of the latter approach is the use of Composite Cross Populations (CCP): progenies of half-diallel crosses between a given number of parental genotypes, left growing in field conditions and reproduced through a cycle of harvest and re-sowing. This is expected to make the crop able to adapt to local environmental and management conditions through natural selection (Goldringer et al. 2006; Rhoné et al., 2008), according to the approach of Evolutionary Breeding (Döring et al., 2011; Phillips and Wolfe, 2005; Suneson, 1956). Regarding diversification at the species level, the strategy of mixing wheat with other crop species has also been explored. In this respect, the use of legume species as intercrops of living mulches is mainly focused on improving weed reduction (Hartwig and Ammon, 2002) and nutrient use efficiency (Stern, 1993).

Overall, crop and cropping system diversification, both at the genetic and at the species level, appears as a key strategy to buffer environmental variation and to optimize resource use efficiency. However, advantages of diversity are not to be taken for granted, as not necessarily higher diversity results in better provision of agro-ecosystem services (Ratnadass et al., 2012). Several tradeoffs between different services may emerge, e.g., the creation 
Table 1

Average soil characteristics in the experimental sites.

\begin{tabular}{|c|c|c|c|c|c|c|c|}
\hline & Sand \% & Silt \% & Clay \% & $\mathrm{pH}$ & Organic matter \% & Total $\mathrm{Ng} \mathrm{Kg}^{-1 \mathrm{~b}}$ & P ppm ${ }^{c}$ \\
\hline Trial \#1 & 43.7 & 33.3 & 23.0 & 8.47 & 1.62 & 1.10 & 12.9 \\
\hline Trial \#2 & 66.3 & 15.2 & 18.5 & 8.03 & 2.75 & 1.38 & 9.34 \\
\hline
\end{tabular}

a Walkley-Black method.

b Kjeldahl method.

c Olsen method.

of a microclimate favourable to the development of diseases in wheat/legume intercropping (Chen et al., 2007). On the other hand, success stories are often limited to case-by-case situations. For example, experiments on cultivar mixtures often show that some mixtures are advantageous in terms of yield, while some other are indifferent or even detrimental (Dai et al., 2012; Mengistu et al., 2010). Therefore, deeper investigation of the mechanisms which translate crop diversity in improved services, involving crop traits and their interactions, is needed. At the same time, research on crop diversification is not exhaustively informative. As an example, advantages in cultivar mixtures are frequently found when compared to their pure components. This kind of results does not imply that the performance of cultivar mixtures is comparable or better than that of, e.g., a cultivar having resulted as the best performing for a certain period of time into a target area, which could be of greater agronomical interest (Kiær et al., 2012).

In Costanzo and Bàrberi (2014), after reviewing diversification strategies related to the main agroecosystem services in wheat, we proposed a categorization of functional agrobiodiversity, to help linking crop traits to agroecosystem services. We categorized functional agrobiodiversity into (i) Functional identity, i.e., a set of homogeneous crop traits related to the expression of a service, (ii) Functional composition, i.e., the complementary effect of cooccurring traits, mainly through complementation and facilitation between effect traits (sensu Hooper et al., 2002), expressed by cooccurring elements, and (iii) Functional diversity, i.e., the direct effect of heterogeneity within the crop stand, through e.g. compensation among response traits (sensu Hooper et al., 2002), on the expression of given agroecosystem services. This categorization could be meaningful as long as it can help cropping system-related decision-making: functional identity addresses cultivar or species choice, functional composition addresses the choice of optimal cultivars or species to combine in cultivar mixtures or intercrops, and functional diversity can address e.g., the choice of parental germplasms to constitute a CCP. In this work, we tested the effect of these three categories on organic wheat production, with special focus on yield and weed reduction, as main target agroecosystem services, by comparing cultivars with different functional identities and varying level of genetic diversity, grown either as wheat only or with a legume living mulch. The experiment was not designed for, nor aimed at a rigorous separation of diversity and identity effects. However, using the categorization explained above, we aimed at reducing the confounding effects of diversity and identity. Thereby, we tested the hypothesis that crop diversification can improve wheat performance in terms of weed reduction and yield and, more specifically, that wheat performance is affected by (i) cultivar functional identity, (ii) cultivar functional diversity, increased through cultivar mixtures and CCPs, and (iii) co-presence of a legume living mulch.

\section{Materials and methods}

\subsection{Experimental site and agronomic management}

A field trial, hereafter "Trial \#1", was carried out in three subsequent seasons, from $2010 / 11$ to $2012 / 13$. This trial was embedded in the Mediterranean Arable System Comparison Trial (MASCOT), a long-term experiment started in 2001 comparing organic and conventional stockless management system, based on the following five-year crop rotation: maize (Zea mays L.), durum wheat (T. durum Desf.), sunflower (Helianthus annuus L.), pigeon bean (Vicia faba $\mathrm{L}$. var. minor), and common wheat (T. aestivum L.), with a hairy vetch (Vicia villosa L.) green manure preceding maize and sunflower in the organic rotation only (Bàrberi and Mazzoncini, 2006). The MASCOT long term experiment occupies a total area of ca. 24 ha in the "Centro Interdipartimentale di Ricerche Agro-Ambientali 'Enrico Avanzi"' (CIRAA) of the University of Pisa (Italy), located in the coastal plain of Pisa (Tuscany, Italy) at $1 \mathrm{~m}$ above sea level $\left(43^{\circ} 39^{\prime} \mathrm{N}\right.$; $\left.10^{\circ} 18^{\prime} \mathrm{E}\right)$. A second wheat field trial, hereafter "Trial \#2", was carried out at CIRAA in the 2012-2013 growing season in a certified organic field following a forage mixture of Trifolium incarnatum L., Vicia sativa L. and Lolium multiflorum Lam. and previously uncultivated. The average soil characteristics of the two experimental sites are shown in Table 1.

In both trials, soil was ploughed at a depth of $25 \mathrm{~cm}$ and fertilised with $1 \mathrm{tha}^{-1}$ of NUTEX organic fertiliser (pelleted manure, $\mathrm{N} / \mathrm{P}_{2} \mathrm{O}_{5} / \mathrm{K}_{2} \mathrm{O}=3 / 3 / 0$ ) prior to wheat sowing. No fertiliser was added during the crop cycle. Wheat was sown in $10 \times 1.5 \mathrm{~m}$ plots in trial $\# 1$ and in $9 \times 1.5$ plots in trial \#2 in 15-cm distant rows. Buffer plots of wheat were sown along field borders.

In trial \#1, first year sowing had to be delayed to 9 February 2011 due to excessive rainfall in autumn 2010. In the second and third year, wheat sowing was done in the originally planned period (12 October 2011 and 15 October 2012). Trial \#2 sowing was done on 19 October 2012 . Weeds were controlled by two passes of a spring tine harrow at wheat tillering stage (BBCH GS 21-30) in Year 1 (20 April 2011) and Year 2 (21 December 2011). Due to excessive and continuous rainfall, harrowing could not be carried out in Year 3 in both trials. Wheat was mechanically harvested on 30 July 2011 in Year 1 and on 12 July 2012 in Year 2, using a Vignoli ${ }^{\circledR}$ plot combineharvester. Mechanical harvest was not performed in Year 3 due to massive crop lodging.

\subsection{Factors and treatments}

This work was carried out through a factorial experiment combining a cultivar factor, represented by wheat pure lines, varietal mixtures and CCPs, and the presence/absence of a legume living mulch.

\subsubsection{Wheat cultivars}

Seven wheat cultivars were tested, belonging to three types: (i) pedigree cultivars representative of modern pure lines, (ii) cultivar mixtures of either modern pure lines or old Italian cultivar, (iii) genetically heterogeneous cultivars, represented by three CCPs.

The pure lines were (i) Bolero (BLR), an Italian pure line widely used in organic farming, here employed as a local control treatment; (ii) Mv Emese (EMS), a Hungarian pure line employed as a common control treatment against local control varieties and commonly tested CCPs in a series of European trials included in the EU-FP7 project SOLIBAM. 
The cultivar mixtures were: (i) a Mixture of Modern Cultivars (MMC), constituted by of seeds of four commercial pure lines Bolero, Albachiara, Blasco and PR22R58 - widely used in Central Italy, used in equal proportions; (ii) a Mixture of Old Italian Cultivars (MOC), constituted by a mixture of seeds of four historic cultivars - Avanzo 3, Frassineto, Torrenova, Virgilio - formerly widely used in Central Italy, used in equal proportions.

The CCPs were (see Table 1 in Döring et al., 2011): (i) Elite CCP (ELI), a Hungarian F4 progeny of 7 high-yielding and highquality modern Hungarian cultivars, constituted by the Agricultural Research Centre of the Hungarian Academy of Science; (ii) Hungarian CCP 1 (HU1), a Hungarian F8 progeny of 12 parentals, created in 2003 with both old and modern cultivars as parentals, constituted by the Agricultural Research Centre of the Hungarian Academy of Science; (iii) Organic Yield-Quality CCP (OYQ), a British F9 progeny of 20 high yielding and high quality old and modern cultivars from across Europe and Russia as parentals, reproduced in a British organic farm, constituted by the Organic Research Centre in the UK.

Seeds of cultivars Bolero, Albachiara, Blasco and PR22R58 were directly obtained from the constitutors or main distributors. Untreated seeds of all those cultivars were not available in Year 1 and Year 2. Thus, conventionally treated seeds were used. In Year 3 , untreated seeds were available for cultivar Blasco, Albachiara and PR22R58, but not for cultivar Bolero. For this latter cultivar, seeds harvested from the previous season were then used. In Year 3 seeds of all cultivars were treated with a copper oxychloride solution (Caffaro ${ }^{\circledR}$ powder, $200 \mathrm{~g} \mathrm{~L}^{-1}$ solution in water), at a rate of $1 \mathrm{~L}$ of solution $100 \mathrm{~kg}^{-1}$ of seeds.

All cultivars were tested in trial \#1, except for MOC which was excluded from the third year trials due to seeds unavailability. In trial \#2, initially planned to compare the performance of different generations of two CCPs, a subset of cultivars was tested: the current generations of ELI and OYQ CCPs, the respective generation of these CCP not reproduced in Year 1 [ELI1; OYQ1], the Hungarian pure line EMS and the mixture of Italian modern cultivars MMC.

\subsubsection{Wheat management systems}

The presence or absence of a legume living mulch was addressed as a second experimental factor. The living mulch was set up as an annual intercrop by contemporarily sowing wheat at a standard density of 450 seeds $\mathrm{m}^{-2}$ and subterranean clover (Trifolium subterraneum L. subsp. brachycalycinum) at a density of 800 seeds $\mathrm{m}^{-2}$. In Years 1 and 2 of Trial \#1, subterranean clover cv. Antas was mechanically sown in-between wheat rows with the same driller used for wheat, while in Year 3, both trials, subterranean clover cv. Clare was broadcast sown immediately before wheat drilling.

\subsection{Samplings and assessments}

Rainfall, maximum and minimum temperatures were recorded on a daily basis at the CIRAA meteorological station $\left(43^{\circ} 40^{\prime} \mathrm{N}\right.$, $10^{\circ} 21^{\prime} \mathrm{E}$ ). Temperature data were used to calculate thermal sums, starting from sowing dates. Growing Degree Days (GDD) were calculated for each day assuming $0^{\circ} \mathrm{C}$ as base temperature (Garcia et al., 2011).

Wheat crop cycle was monitored according to the BBCH decimal scale for phenological development (Meier, 2011). We divided crop cycle into three phases (HGCA, 2008): (i) the foundation phase, from sowing to GS 31, including emergence and tillering growth stages, (ii) the construction phase, from GS 31 to GS 59, including stem elongation, booting and ear extrusion stages; (iii) the production phase, from GS 59 until harvest maturity, including grain filling and ripening stages.

In each experiment, crop development was monitored through phenological assessments done on individual plants randomly chosen in each plot. The completion of ear extrusion (BBCH GS 59) was chosen as an indicator of crop earliness. The number of individual plants plot $^{-1}$ assessed and the interval between assessments varied according to wheat growth stage: (i) during the foundation phase, when development and growth were slow, five to ten plants plot $^{-1}$ were assessed approximately every two weeks, (ii) during the construction phase, when development was faster and variability within wheat cultivars was more evident, 15-40 plants plot ${ }^{-1}$ were assessed at least weekly or, in correspondence of the heading stage (BBCH GS 51-59), twice a week.

Canopy height was recorded every two phenological assessments by measuring the height of the highest point (excluding awns) of every plant chosen for phenological assessments.

Symptoms of the leaf spot disease complex (Pyrenophora triticirepentis, Mycosphaerella graminicola, Parastagonospora nodorum) were assessed in the second and third years. Symptoms intensity was assessed on the flag leaf of 10-20 individual plants plot ${ }^{-1}$ after BBCH GS 65 according to a 0-9 visual scale (Stubbs et al., 1986; Flath and Cooke, 2006), and used for the calculation of the McKinney index of disease severity (McKinney, 1923).

Weed abundance and community composition were assessed in each plot during late tillering stages (BBCH GS 21-30). Weed abundance was assessed by measuring density or visually estimating cover by species in one or two quadrates plot $^{-1}$ of $25 \times 30$ or $45 \times 50 \mathrm{~cm}$. The wider quadrate was used when within-plot variability in wheat and weeds density was high. Weed cover was estimated instead of weed density in just one quadrate when weed abundance was too high to be accurately quantified in terms of density. Destructive samplings were carried out at BBCH GS 31 and 65 (reference growth stage of cultivar EMS). In Years 2 and 3 of Trial \#1, above-ground weed biomass at BBCH GS 31 was sampled in the same fixed quadrates previously used to assess weed abundance. In 2012/13 one of the two quadrates used for assessing weed species density was sampled at BBCH GS 31 and the other at BBCH GS 65.

Wheat grain yield and yield components were assessed before mechanical harvest. Wheat above-ground biomass was sampled on two (in 2011 and 2012) or one (in 2013) quadrates of $0.45 \times 1 \mathrm{~m}$ in each plot, placed in the central part of each plot at a distance of at least $0.5 \mathrm{~m}$ from where previous destructive samples were taken. Wheat above-ground biomass was cut at the soil level, separated from weeds and clover residues, and partitioned into spikes and straw. Spikes were counted, weighed after being oven-dried at $60^{\circ} \mathrm{C}$ until constant weight, and threshed, and kernels were subsequently weighed. Thousand kernels weight (TKW) was obtained by weighing five independent samples of 100 seeds plot ${ }^{-1}$ after oven-drying at $100^{\circ} \mathrm{C}$ until constant weight.

\subsection{Statistical analysis}

Field trials were organised as two-way randomised complete block (RCB) design, and data were analysed through a two-ways RCB ANOVA considering (i) wheat cultivar and (ii) living mulch presence as factors. As far as the first year of Trial \#1 is concerned, a further analysis has been run after excluding experimental units with severe crop failure (hereafter referred to as 'selected dataset'). Specifically, only the experimental units showing a wheat density $>100$ plants $\mathrm{m}^{-2}$ were retained, and analysed through a two-way completely randomized ANOVA. Non parametric analyses were run when data transformation was unable to homogenize error variances. The Kruskal-Wallis rank sum test was applied to test the effect of wheat cultivars (treatments $>2$ ), while the Wilcoxon-Mann-Whitney U test was applied to test the effect of living mulch (treatments $=2$ ). All statistical analyses were run using the software "R", version 3.0.2 (R Development Core Team, 2011).

The wheat cultivar factor in Trial \#1 was split into a set of six orthogonal linear contrasts (five in 2012/13) in order to unravel functional identity and functional diversity effects on each response 
Table 2

Set of orthogonal linear contrasts, grouping of cultivars and specific hypothesis addressed by each contrast.

\begin{tabular}{|c|c|c|c|c|}
\hline \multicolumn{5}{|l|}{ Trial \#1 } \\
\hline & Contrast & Cultivars groups & & Specific hypothesis \\
\hline Contrast $1^{\mathrm{a}}$ & $\begin{array}{l}\text { Old vs Modern } \\
\text { cultivars }\end{array}$ & Old: $\mathrm{MOV}^{\mathrm{a}}$ & $\begin{array}{l}\text { Modern: BLR; ELI; } \\
\text { EMS; HU1; MMC; } \\
\text { OYQ }\end{array}$ & $\begin{array}{l}\text { Differences between cultivars due to early vs modern } \\
\text { breeding programmes }\end{array}$ \\
\hline Contrast 2 & Pure Lines vs CCPs & $\begin{array}{l}\text { Pure Lines: BLR; } \\
\text { EMS; MMC }\end{array}$ & $\begin{array}{l}\text { CCPs: ELI; HU1; } \\
\text { OYQ }\end{array}$ & $\begin{array}{l}\text { Differences due to functional diversity and functional } \\
\text { identity/geographical origin }\end{array}$ \\
\hline Contrast 3 & $\begin{array}{l}\text { Italian vs } \\
\text { Hungarian Pure } \\
\text { Lines }\end{array}$ & Italian: BLR; MMC & Hungarian: EMS & Differences due to functional identity/geographical origin \\
\hline Contrast 4 & $\begin{array}{l}\text { Italian Pure Line } \\
\text { Monocrop vs } \\
\text { Mixture }\end{array}$ & Monocrop: BLR & Mixture: MMC & Mixture effect \\
\hline Contrast 5 & $\begin{array}{l}\text { Hungarian vs } \\
\text { British CCPs }\end{array}$ & $\begin{array}{l}\text { Hungarian: ELI; } \\
\text { HU1 }\end{array}$ & British: OYQ & $\begin{array}{l}\text { Differences due to parentals, generation and geographical } \\
\text { origin }\end{array}$ \\
\hline Contrast 6 & $\begin{array}{l}\text { Within Hungarian } \\
\text { CCPs }\end{array}$ & ELI & HU1 & Differences due to parentals and generation \\
\hline \multicolumn{5}{|l|}{ Trial \#2 } \\
\hline Contrast 1 & Pure Lines vs CCPs & $\begin{array}{l}\text { Pure Lines: EMS; } \\
\text { MMC }\end{array}$ & $\begin{array}{l}\text { CCPS: ELI; ELI1; } \\
\text { OYQ; OYQ1 }\end{array}$ & $\begin{array}{l}\text { Differences due to functional diversity and functional } \\
\text { identity/geographical origin }\end{array}$ \\
\hline Contrast 2 & $\begin{array}{l}\text { Italian vs } \\
\text { Hungarian Pure } \\
\text { Lines }\end{array}$ & Italian: MMC & Hungarian: EMS & Differences due to functional identity/geographical origin \\
\hline Contrast 3 & $\begin{array}{l}\text { Hungarian vs } \\
\text { British CCPs }\end{array}$ & $\begin{array}{l}\text { Hungarian: ELI; } \\
\text { ELI1 }\end{array}$ & British: OYQ; OYQ1 & $\begin{array}{l}\text { Differences due to parentals, generation and geographical } \\
\text { origin }\end{array}$ \\
\hline Contrast 4 & Within ELI, F6 vs F5 & F6: ELI & F5: ELI1 & Differences due to having been grown in $2010 / 11$ at CIRAA \\
\hline Contrast 5 & $\begin{array}{l}\text { Within OYQ, F11 vs } \\
\text { F10 }\end{array}$ & F11: OYQ & F10: OYQ1 & Differences due to having been grown in $2010 / 11$ at CIRAA \\
\hline
\end{tabular}

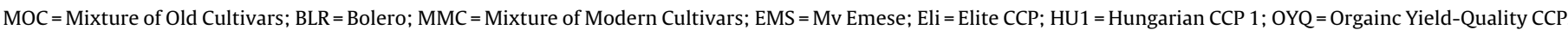

a Excluded in 2012/13.

variable in an experimental design where the two effects were confounded. Similarly, five contrasts were set for Trial \#2 (Table 2). The main objective of this analysis was to test the effect of CCPs against modern pure lines. As all the CCP were of foreign origin, differences between CCP and modern pure lines BLR, MMC and EMS may be due to both functional diversity and functional identity, the latter possibly being influenced by the different geographical origins. Linear contrasts of Italian $v s$ Hungarian pure lines aimed at detecting the presence/absence of a functional identity effect, mainly influenced by geographical origin, over the response variable. Similarly, the effects of cultivar mixtures were considered meaningful only when contrasting the mixture of Italian modern pure lines against an individual Italian modern pure line.

\section{Results}

Wheat crop had a very low establishment in 2010/11 (85.6 \pm 4.8 plants $\mathrm{m}^{-2}$ ) with minimum peaks of 13.3 plants $\mathrm{m}^{-2}$ with no significant differences either by cultivar $(p=0.15)$ or due to the living mulch (0.86), indicating a severe crop failure. Data presented hereafter for Year 1 are therefore referred to the selected dataset. In contrast, in 2011/12 and 2012/13, wheat establishment was optimal, with $278.1 \pm 4.44$ and $406.0 \pm 6.6$ plants $\mathrm{m}^{-2}$, respectively.

\subsection{Climatic pattern}

The three growing seasons (2010/11,2011/12 and 2012/13) had very different rainfall patterns (Fig. 1). In 2010/11, total rainfall from October to June was $933 \mathrm{~mm}, 27.9 \%$ higher than the average of $719 \mathrm{~mm}$ recorded in the period 1993-2013. An amount of $548.7 \mathrm{~mm}$ of rain fell from October to December, with periods without rains no longer than four days until the end of November. A 15-day period without significant rainfall (less than $0.5 \mathrm{~mm} \mathrm{day}^{-1}$ ), starting on 21 January 2011, made the sowing of field Trial \#1 possible on 9 February 2013. After sowing, temperatures were relatively high, with average never lower than $6^{\circ} \mathrm{C}$ and minimum values never under $0{ }^{\circ} \mathrm{C}$. High rainfall continued until the end of March, with $277 \mathrm{~mm}$. Then, a very dry period started, with $21 \mathrm{~mm}$ of rain in April and only $8.2 \mathrm{~mm}$ in May. Temperatures were also constantly increasing until reaching maximum peaks of above $30^{\circ} \mathrm{C}$ which lasted from the second week of June until crop harvest.

In $2011 / 12$, the climate pattern was unusually dry, as only $497 \mathrm{~mm}$ of rain, $31 \%$ less than the 20 -year average, fell from October to June. Rainfall was concentrated in December, with $132 \mathrm{~mm}-$ $85 \mathrm{~mm}$ in just one event on 12 December - and April, with $159 \mathrm{~mm}$. In contrast, only $61 \mathrm{~mm}$ fell in the October-November period, and only $68.4 \mathrm{~mm}$ from January to March. This unusually dry winter was also characterised by relatively low temperatures, with more than three subsequent weeks in January-February with minimum temperature falling down to $-5^{\circ} \mathrm{C}$ and average temperature close to $0^{\circ} \mathrm{C}$.

In $2012 / 13$ the total rainfall in the October-June period exceeded the 20 -year average by $83 \%(1320 \mathrm{~mm})$. Rainfall was very intense until mid-May, with a monthly peak of $297 \mathrm{~mm}$ in March and daily peaks of $122 \mathrm{~mm}$ on 11 November and $88 \mathrm{~mm}$ on 12 March. Rainfall was also almost uninterrupted, as periods with no rainfall did not exceed 4 days until the end of May. Temperatures were moderately high troughout the entire growing season, with averages never lower than $6^{\circ} \mathrm{C}$, minimum values never under $0^{\circ} \mathrm{C}$ and maximum values never under $10^{\circ} \mathrm{C}$.

\subsection{Wheat cultivar characterization}

\subsubsection{Phenology}

Overall, the tested cultivars showed considerable differences in terms of growing cycle length, with the Italian pure lines clearly earlier than the Hungarian and the British ones, and the Old cultivars showing an intermediate growth cycle. The CCP showed a clearly later ear extrusion, with a two-week delay in the onset of this stage compared to the Italian modern cultivars, while the Hungarian modern cultivar EMS had an intermediate pattern, showing a 7-10 days delay compared to Italian modern cultivars. Slight but 
Table 3

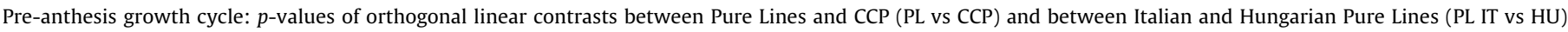
Symbols "<" and ">" indicate whether the first term of the constrast has a lower or higher mean, respectively, than the second term.

\begin{tabular}{|c|c|c|c|}
\hline & 2011 & 2012 & 2013 \\
\hline \multicolumn{4}{|c|}{ Thermal time (GDDs from sowing) to complete ear extrusion (BBCH GS 59) } \\
\hline ANOVA p for POP & $3.6 \mathrm{e}^{-5}$ & $2 \mathrm{e}^{-16}$ & $2 \mathrm{e}^{-16}$ \\
\hline PL vs CCP & $1.7 \mathrm{e}^{-6}(<)$ & $2 \mathrm{e}^{-16}(<)$ & $2 \mathrm{e}^{-16}(<)$ \\
\hline PL IT vs HU & $0.009(<)$ & $3.2 \mathrm{e}^{-15}(<)$ & $0.006(<)$ \\
\hline \multicolumn{4}{|c|}{ Thermal time (GDDs from sowing) of the construction phase, from the onset of stem extension (BBCH GS 31) to complete ear extrusion (BBCH GS 59) } \\
\hline ANOVA p for POP & 0.127 & $7.9 \mathrm{e}^{-11}$ & $4.0 \mathrm{e}^{-9}$ \\
\hline PL vs CCP & $0.085(<)$ & $1.09 \mathrm{e}^{-9}(<)$ & $3.1 \mathrm{e}^{-11}(<)$ \\
\hline PL IT vs HU & $0.013(<)$ & $7.71 \mathrm{e}^{-5}(>)$ & $0.081(<)$ \\
\hline
\end{tabular}

significant differences also emerged within the CCP, with the British ones showing a two-days delay compared to the Hungarian ones in all three years (Table 3).

During the early growth stages tillering ability, expressed as the number of supplementary tillers plant ${ }^{-1}$, followed a similar pattern. Both EMS and the CCPs had a significantly higher tillering ability than the Italian modern cultivars in all three years. However, cultivar EMS had an intermediate, more variable pattern, with values close to those of the CCP crosses only in Year 2. In particular, the British OYQ CCP had a very stable tillering ability across years (coefficient of variation $=8 \%$ ) and showed by far the highest production of tillers in the late sowing condition of Year 1 (Fig. 2).

The partitioning of pre-anthesis growth into a foundation phase - up to BBCH GS 31 - and a construction phase - from BBCH GS 31 to GS 59 - also revealed distinct patterns. The thermal units needed to conclude the foundation phase varied upon cultivar in Year 1 (Kruskal-Wallis test: $p=0.0008$ ), Year 2 (Kruskal-Wallis test: $p=7.6 \mathrm{e}^{-06}$ ) and Year 3 (Kruskal-Wallis test: $p=2.8 \mathrm{e}^{-06}$ ) of Trial \#1. CCP tended to start stem extension later than modern cultivars, and within the latter, the Hungarian had a significant lag behind the Italian.

Significant differences were also found for the thermal time needed to complete the construction phase, which was longer in the CCP than in the pure lines BLR, MMC and EMS. However, in this case, the CCP pattern was not aligned with that of cultivar EMS, which construction phase was as long as that of the modern Italian cultivar (Table 3, Fig. 3).

\subsubsection{Canopy height}

Wheat cultivars were highly differentiated upon canopy height, and their ranking based on height changed according to the development phase. In all three years we observed a clearly higher canopy in the early phases in the Italian pure lines cultivars BLR and MMC. Taller canopy of Italian pure lines during tillering was mainly linked to their erectophile growth habit. In contrast, the Hungarian pure line EMS and all the CCPs had a markedly prostrate growth habit.

Instead, during the stem extension phase, the CCPs and EMS had a faster height increase, and became taller, than BLR and MMC. The height ranking was then inverted at crop maturity, with the CCPs showing a significantly taller canopy than the pure lines. Within the latter, the Hungarian was taller than the Italian ones.

The MOC showed a clearly distinct pattern from any other tested cultivar. Its canopy height was similar to that of BLR and MMC during the Foundation phase, while it showed a fast height increase during the Construction phase. As a result, the MOC had a 37\% taller canopy than all the other cultivars both in Year 1 and 2 of Trial \#1 (Table 4).

\subsubsection{Response to diseases}

Among biotic stresses, we observed outbreaks of the leaf spot disease complex. The CCPs showed a good tolerance to these pathogens. Severity of symptoms on flag leaves, expressed by the
McKinney Index, was affected by the cultivar in Year 2 and Year 3 of Trial \#1 and in Trial \#2. The CCP showed lower disease severity than the pure lines and, among these latter, the Hungarian EMS was significantly more affected than the Italian pure lines BLR and MMC. Interestingly, in Trial \#2 the presence of the living mulch reduced severity of the leaf spot complex by $37 \%$ on average (Fig. 4 ).

In spring 2013, wheat in Trial \#1 was affected by severe lodging. Two main causes were identified for this problem: (i) the occurrence of storms during May and (ii) an outbreak of stem-base diseases. Clear symptoms of eyespot (Oculimacula yallundae) were detected on the stem base of wheat plants in all the tested cultivars. No clear differences between cultivars were detected in terms of occurrence of eyespot symptoms and lodging susceptibility. All the tested cultivars were completely lodged in half of the experimental field. In the less damaged part of the field, only 3 out of 8 plots of the Italian pure lines showed low lodging, while all the other plots were uniformly affected.

\subsection{Crop-weed interactions}

\subsubsection{Wheat and weed biomass}

Wheat biomass pattern showed that the Italian cultivars had a faster growth than the Hungarian and British cultivars during the early stages. In field Trial \#1 we found clear differences in terms of early crop biomass production between cultivars at BBCH GS 31 . Except in 2010/11, when no differences were found, the pure lines produced a higher biomass than CCPs and with higher values in BLR and MMC than in EMS. At wheat flowering (GS 65), the biomass of wheat cultivars maintained a similar pattern.

These patterns were partly consistent with differences in weed biomass accumulation. In 2011/12, weed biomass at GS 65 was significantly lower in MOC than in all the other cultivars by $43 \%$ on average. No differences were found between pure lines and CCPs $(p=0.40)$ but, within the pure lines, weed biomass in BLR and MMC was $28 \%$ lower than in EMS (Fig. 5).

In $2012 / 13$, weed biomass at GS 31 was $18.6 \%$ lower in the pure lines than in CCPs, with $18.3 \%$ lower values in BLR and MMC than in EMS (Fig. 6). Wheat and weed biomasses at GS31 were clearly negatively correlated ( $n=48$, Pearson's $r=-0.602$, $p=6.06 \mathrm{e}^{-6}$ ). However, no differences in weed growth at wheat flowering (GS 65) could be attributed to wheat biomass differences among cultivars.

\subsubsection{Living mulch effects on wheat and weeds}

Subterranean clover exhibited variable growth patterns among years and, consequently, it showed variable effects on wheat and weeds. In Trial \#1, clover early growth, measured at the onset of wheat stem extension, was relatively low in all three years. However, successive clover growth varied considerably among years. For example, clover biomass at wheat GS 65 was 97\% higher in Year 3 than in Year 2 . This was probably due to the very cold and dry winter climate in Year 2. Moreover, in Year 3 (Trial \#2), clover growth 


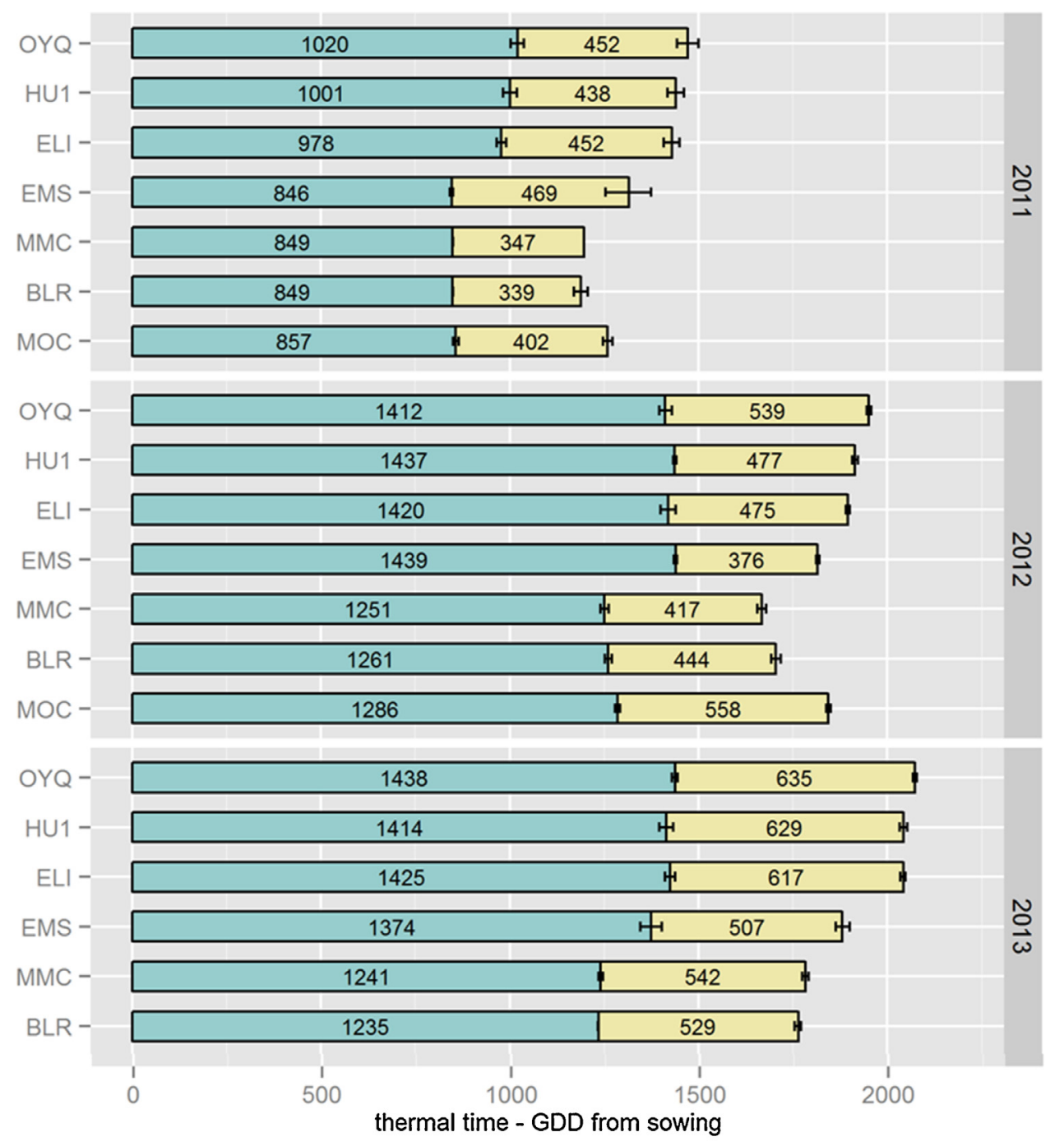

\section{Phase 1_foundation $/ 2$ construction}

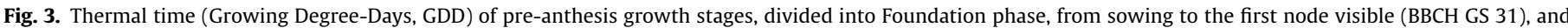

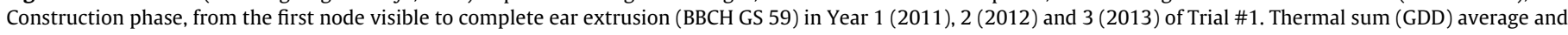
standard error of each phase is indicated into the bars.

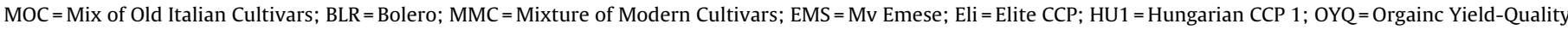
CCP.

was much higher than in every year of Trial \#1 at both wheat GS 31 and GS 65.

Wheat biomass at maturity was reduced by the presence of the living mulch by $29 \%$ in Year 1 of Trial \#1 and by 33\% in Trial \#2 $(2012 / 13)$. In this latter experiment only, clover reduced wheat growth by $32 \%$ already at an early stage. In contrast, differences in wheat growth due to living mulch were observed neither in 2011/12 nor in 2012/13 (Trial \#1) (Table 5).

Compared to the pure crop, the living mulch system significantly decreased total weed density at wheat late tillering (BBCH GS 30) by $41 \%$ in Year 1 and by $30 \%$ in Year 3 of Trial \#1. However, the living mulch was not equally effective on the whole weed community, since it significantly reduced dicotyledonous but not monocotyledonous weed density (Fig. 7). Overall, we observed a consistent reduction in dicotyledonous weeds relative abundance due to the presence of the living mulch.

Changes in dicots/monocots relative abundance did not result in a stable effect on weed growth. In fact, no reduction in weed biomass at wheat BBCH GS 31 was found. Weed growth at wheat flowering (BBCH GS 65) was significantly suppressed by the presence of the living mulch in 2012/13, by 25.8 and $27.8 \%$ in Trial \#1 and \#2 respectively, i.e. those which showed the highest subterranean clover growth (Table 5).

\subsection{Yield and yield components}

\subsubsection{Wheat grain production}

In the overall dataset of Year 1, wheat grain yield was very low with an average of $0.12 \pm 0.01 \mathrm{tha}^{-1}$ and minimum extremes of $0.02 \mathrm{tha}^{-1}$, and no significant differences were found either by cultivar $(p=0.42)$ or due to the living mulch $(p=0.08)$. Data presented hereafter for Year 1 are therefore related to the selected dataset. Grain yield was strongly influenced by the extreme climatic variability of the three years of trials, with mean values of $1.18 \pm 0.09 \mathrm{tha}^{-1}$ in Year $1,4.04 \pm 1.00 \mathrm{tha}^{-1}$ in Year 2, $1.42 \pm 0.10 \mathrm{t} \mathrm{ha}^{-1}$ (Trial \#1) and $0.64 \pm 0.02 \mathrm{tha}^{-1}$ (Trial \#2) in Year 3 . The living mulch decreased wheat yield by $31 \%$ in Year 1 of Trial $\# 1(p=0.012)$ and by $51 \%$ in Trial \#2 $(2012 / 13)\left(p=9.1 \mathrm{e}^{-5}\right)$. In both 
Table 4

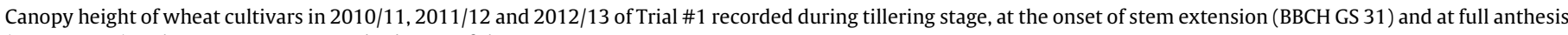
(BBCH GS 65). Values are means \pm standard error of the means.

\begin{tabular}{|c|c|c|c|c|c|c|c|c|c|}
\hline \multirow[t]{2}{*}{ Cultivar } & \multicolumn{3}{|c|}{ Height during tillering (BBCH GS 21-30) } & \multicolumn{3}{|c|}{$\begin{array}{l}\text { Height at the onset of stem extension } \\
\text { (BBCH GS 31) }\end{array}$} & \multicolumn{3}{|c|}{ Height at full anthesis (BBCH GS 65) } \\
\hline & $\begin{array}{l}2010 / 11 \\
\mathrm{~cm}\end{array}$ & $\begin{array}{l}2011 / 12 \\
\mathrm{~cm}\end{array}$ & $\begin{array}{l}2012 / 13 \\
\mathrm{~cm}\end{array}$ & $\begin{array}{l}2010 / 11 \\
\mathrm{~cm}\end{array}$ & $\begin{array}{l}2011 / 12 \\
\mathrm{~cm}\end{array}$ & $\begin{array}{l}2012 / 13 \\
\mathrm{~cm}\end{array}$ & $\begin{array}{l}2010 / 11 \\
\mathrm{~cm}\end{array}$ & $\begin{array}{l}2011 / 12 \\
\mathrm{~cm}\end{array}$ & $\begin{array}{l}2012 / 13 \\
\mathrm{~cm}\end{array}$ \\
\hline $\begin{array}{l}\text { MOC } \\
\text { Pure lines }\end{array}$ & $11.90 \pm 0.43$ & $17.63 \pm 0.76$ & - & $28.78 \pm 1.48$ & $37.57 \pm 2.00$ & - & $75.38 \pm 1.61$ & $124.84 \pm 6.02$ & - \\
\hline BLR (IT) & $11.31 \pm 0.55$ & $18.47 \pm 0.79$ & $14.70 \pm 0.33$ & $28.20 \pm 1.83$ & $38.53 \pm 3.25$ & $47.28 \pm 1.50$ & $47.15 \pm 1.15$ & $72.64 \pm 3.56$ & $83.25 \pm 2.30$ \\
\hline MMC (IT) & $11.77 \pm 0.41$ & $19.27 \pm 1.07$ & $14.81 \pm 0.32$ & $29.48 \pm 0.30$ & $46.05 \pm 2.43$ & $51.75 \pm 1.99$ & $45.87 \pm 0.35$ & $76.80 \pm 4.46$ & $87.10 \pm 2.65$ \\
\hline $\begin{array}{l}\text { EMS (HU) } \\
\text { CCPs }\end{array}$ & $9.75 \pm 0.32$ & $12.77 \pm 0.58$ & $13.93 \pm 0.50$ & $25.39 \pm 1.84$ & $26.02 \pm 0.81$ & $34.38 \pm 3.06$ & $50.65 \pm 0.55$ & $92.44 \pm 1.93$ & $93.10 \pm 4.02$ \\
\hline $\operatorname{ELI}(\mathrm{HU})$ & $9.55 \pm 0.59$ & $9.90 \pm 0.52$ & $9.03 \pm 0.36$ & $24.86 \pm 1.50$ & $27.55 \pm 2.60$ & $30.16 \pm 2.24$ & $58.16 \pm 1.19$ & $99.03 \pm 5.55$ & $97.92 \pm 3.12$ \\
\hline HU1 (HU) & $8.93 \pm 0.39$ & $9.87 \pm 0.39$ & $9.59 \pm 0.34$ & $17.25 \pm 0.45$ & $26.30 \pm 1.79$ & $29.41 \pm 3.29$ & $64.14 \pm 1.62$ & $105.51 \pm 4.98$ & $99.41 \pm 5.66$ \\
\hline OYQ(UK) & $6.60 \pm 0.49$ & $9.17 \pm 0.71$ & $8.27 \pm 0.28$ & $17.06 \pm 2.04$ & $26.50 \pm 1.66$ & $30.71 \pm 2.03$ & $60.79 \pm 2.03$ & $101.63 \pm 2.59$ & $101.92 \pm 2.81$ \\
\hline \multicolumn{10}{|c|}{$\begin{array}{l}\text { Anova } p \text {-values by 'cultivar' and p-values of Pure Lines vs CCP and of Italian (IT) vs Hungarian (HU) Pure Lines orthogonal linear contrasts. Symbols '>' and '<' } \\
\text { indicate whether the average of the first term is higher or lower, respectively, than the average of the second term of the contrast }\end{array}$} \\
\hline Anova p by 'cultivar' & $9.9 \mathrm{e}^{-7}$ & $3.3 e^{-14}$ & $<2 \mathrm{e}^{-16}$ & $1.8 \mathrm{e}^{-11}$ & $8.6 \mathrm{e}^{-10}$ & $<2 \mathrm{e}^{-16}$ & $2.6 \mathrm{e}^{-9}$ & $1.9 \mathrm{e}^{-13}$ & $2.8 \mathrm{e}^{-6}$ \\
\hline Old vs Modern & $0.0001(>)$ & $1.04 \mathrm{e}^{-6}(>)$ & - & $9.8 \mathrm{e}^{-12}(>)$ & $0.0049(>)$ & - & $6.3 e^{-10}(>)$ & $2.2 \mathrm{e}^{-12}(>)$ & - \\
\hline Pure Lines vs CCP & $2.3 e^{-6}(>)$ & $1.8 \mathrm{e}^{-14}(>)$ & $<2 \mathrm{e}^{-16}(>)$ & $3.5 \mathrm{e}^{-10}(>)$ & $5.7 \mathrm{e}^{-8}(>)$ & $<2 \mathrm{e}^{-16}(>)$ & $7.4 \mathrm{e}^{-09}(<)$ & $1.3 \mathrm{e}^{-10}(<)$ & $1.9 \mathrm{e}^{-7}(<)$ \\
\hline IT vs HU Pure Lines & $0.006(>)$ & $2.2 \mathrm{e}^{-8}(>)$ & $0.0497(>)$ & $0.028(>)$ & $1.3 e^{-8}(>)$ & $5.2 \mathrm{e}^{-12}(>)$ & $0.0175(<)$ & $1.4 \mathrm{e}^{-5}(<)$ & $0.008(<)$ \\
\hline
\end{tabular}

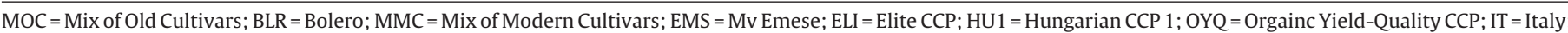
$\mathrm{HU}=$ Hungary; UK = United Kingdom

Table 5

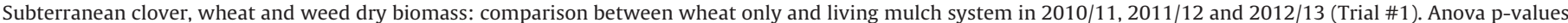
by 'system' are indicated.

\begin{tabular}{|c|c|c|c|c|c|c|}
\hline & \multirow{2}{*}{$\begin{array}{l}\text { Sampling date and wheat } \\
\text { growth stage }\end{array}$} & \multirow{2}{*}{$\begin{array}{l}\text { Subclover dry biomass } \\
\left(\mathrm{g} \mathrm{m}^{-2}\right)\end{array}$} & \multicolumn{2}{|c|}{ Wheat dry biomass $\left(\mathrm{g} \mathrm{m}^{-2}\right)$} & \multicolumn{2}{|c|}{ Weeds dry biomass $\left(\mathrm{g} \mathrm{m}^{-2}\right.$ ) } \\
\hline & & & Living Mulch & Wheat Only & Living Mulch & Wheat Only \\
\hline \multirow[t]{2}{*}{2011} & 5 May GS 31 & $35.9 \pm 7.3$ & $\begin{array}{l}50.2 \pm 6.4 \\
p=0.306\end{array}$ & $62.2 \pm 6.7$ & $\begin{array}{l}31.0 \pm 6.2 \\
p=0.347\end{array}$ & $39.9 \pm 7.9$ \\
\hline & 8-15 July GS 89 & n.a. & $\begin{array}{l}176.8 \pm 15.9 \\
p=0.024\end{array}$ & $249.0 \pm 25.0$ & $\begin{array}{l}115.7 \pm 15.7 \\
p=0.789\end{array}$ & $114.2 \pm 16.3$ \\
\hline \multirow[t]{2}{*}{2012} & 25 March GS 31 & $24.0 \pm 2.3$ & $\begin{array}{l}315.1 \pm 20.6 \\
p=0.890\end{array}$ & $318.4 \pm 26.6$ & $\begin{array}{l}65.6 \pm 7.4 \\
p=0.129\end{array}$ & $52.7 \pm 5.6$ \\
\hline & 15 May GS 65 & $66.3 \pm 6.2$ & $\begin{array}{l}826.3 \pm 32.1 \\
p=0.287\end{array}$ & $794.9 \pm 35.8$ & $\begin{array}{l}184.7 \pm 15.9 \\
p=0.052\end{array}$ & $150.5 \pm 15.2$ \\
\hline \multirow[t]{2}{*}{2013 Trial \#1 } & 28 March GS31 & $30.4 \pm 3.6$ & $\begin{array}{l}323.1 \pm 26.7 \\
p=0.91\end{array}$ & $321.0 \pm 26.6$ & $\begin{array}{l}25.6 \pm 1.8 \\
p=0.588\end{array}$ & $26.6 \pm 1.9$ \\
\hline & 13 May GS65 & $127.9 \pm 13.1$ & $\begin{array}{l}861.3 \pm 53.8 \\
p=0.650\end{array}$ & $840.7 \pm 44.3$ & $\begin{array}{l}117.1 \pm 10.1 \\
p=0.011\end{array}$ & $157.8 \pm 13.6$ \\
\hline \multirow[t]{2}{*}{2013 Trial \#2 } & 30 May GS31 & $196.4 \pm 19.7$ & $\begin{array}{l}109.8 \pm 11.2 \\
p=0.003\end{array}$ & $161.2 \pm 18.3$ & $\begin{array}{l}48.85 .2 \\
p=0.154\end{array}$ & $59.8 \pm 4.6$ \\
\hline & 27 May GS65 & $276.5 \pm 41.3$ & $\begin{array}{l}186.6 \pm 22.7 \\
p=0.006\end{array}$ & $279.5 \pm 22.4$ & $\begin{array}{l}196.915 .8 \\
p=0.004\end{array}$ & $272.8 \pm 19.2$ \\
\hline
\end{tabular}

these cases, wheat above-ground biomass production and grain yield were generally very low and not differentiated by cultivar. On the contrary, in the second and third year of Trial \#1, no effect of the living mulch was found on grain yield, while significant variation patterns were found among wheat cultivars ( $p=0.004$ and $p=0.003$ in $2011 / 12$ and 2012/13, respectively).

In 2011/12, MOC was the least yielding compared to all the other cultivars. The pure lines out yielded the CCPs by $16.4 \%$ in Year 2 and by $69.5 \%$ in Year 3 of Trial \#1. However, while in Year 2 no differences were found within the pure lines, in Year 3 BLR and MMC yielded 92\% than the Hungarian EMS (Fig. 8).

\subsubsection{Yield components}

Yield components analysis in the three years of Trial \#1 shed light on the different yield formation strategies of the tested cultivars. Ear density was never affected by wheat cultivar, but was quite variable between years. In Year 1, ear density was very low $\left(142.1 \pm 11.1\right.$ ears $\left.\mathrm{m}^{-2}\right)$, mainly due to low wheat establishment. Instead, in Years 2 and 3, ears density increased up to $383.5 \pm 5.2$ and $321.8 \pm 13.6$ ears $\mathrm{m}^{-2}$, respectively (Table 6).
In contrast, the Thousand Kernels Weight (TKW) was highly differentiated by cultivar. In all cases, CCPs had a lower TKW than the pure lines. However, the pure lines vs CCP and the Italian (BLR and MMC) vs Hungarian (EMS) pure lines contrasts were both significant but divergent, as EMS maintained a higher TKW than the Italian cultivars in all years. Despite their common, foreign origin, thus, EMS was not aligned with the CCPs as for average kernel weight. BLR and MMC maintained a similar pattern in all years, with a slight increase of the total average from Year 1 to Year 2 and an important decrease from Year 2 to Year 3 (Table 6). Low yield of the CCPs in Year 3 seems therefore linked to a lower number of kernels ear ${ }^{-1}$, but not of spikelets number ear ${ }^{-1}$. A further

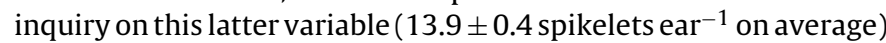
showed that differences among cultivars were slightly significant (Kruskal-Wallis test $p=0.042)$. However, ELI $(15.8 \pm 1.1)$ and OYQ $(14.4 \pm 0.1)$ had significantly higher values than EMS $(12.5 \pm 1.1)$ (Wilcoxon-Mann-Withney test $p=0.029$ in both comparisons). No significant other differences emerged.

Harvest Index (HI) also showed differences between cultivars not linked to geographical origin, except for Year 3. MOC showed the lowest $\mathrm{HI}$ in both Year 1 and 2 (16.8\% and 22.3\% less than the 
Table 6

Yield components of wheat cultivars in 2010/11, 2011/12 and 2012/13 of Trial \#1. Values are means \pm standard error of the means.

\begin{tabular}{|c|c|c|c|c|c|c|c|c|c|}
\hline \multirow[t]{2}{*}{ Cultivar } & \multicolumn{3}{|l|}{ Ears density } & \multicolumn{3}{|l|}{ TKW } & \multicolumn{3}{|c|}{ Harvest index $\left({ }^{*}\right)$} \\
\hline & $2010 / 11$ & $2011 / 12$ & $2012 / 13$ & $2010 / 11$ & $2011 / 12$ & $2012 / 13$ & $2010 / 11$ & $2011 / 12$ & $2012 / 13$ \\
\hline & Ears $\mathrm{m}^{-2}$ & Ears $\mathrm{m}^{-2}$ & Ears $\mathrm{m}^{-2}$ & $\mathrm{~g}$ & $\mathrm{~g}$ & $\mathrm{~g}$ & & & \\
\hline MOC & $161.1 \pm 37.5$ & $375.7 \pm 10.7$ & - & $43.6 \pm 0.4$ & $47.7 \pm 0.9$ & - & $0.42 \pm 0.02$ & $0.32 \pm 0.02$ & - \\
\hline \multicolumn{10}{|l|}{ Pure lines } \\
\hline $\operatorname{BLR}(\mathrm{IT})$ & $158.3 \pm 27.6$ & $390.2 \pm 18.8$ & $381.7 \pm 47.5$ & $33.3 \pm 1.1$ & $34.5 \pm 2.0$ & $27.8 \pm 0.6$ & $0.49 \pm 0.02$ & $0.43 \pm 0.01$ & $0.31 \pm 0.02$ \\
\hline MMC (IT) & $138.2 \pm 35.6$ & $401.7 \pm 7.5$ & $320.0 \pm 15.07$ & $38.0 \pm 0.36$ & $38.4 \pm 0.6$ & $30.4 \pm 2.3$ & $0.57 \pm 0.01$ & $0.43 \pm 0.00$ & $0.26 \pm 0.01$ \\
\hline EMS (HU) & $123.9 \pm 28.8$ & $385.4 \pm 12.2$ & $290.0 \pm 50.2$ & $42.7 \pm 0.7$ & $45.1 \pm 0.7$ & $33.3 \pm 1.7$ & $0.55 \pm 0.01$ & $0.43 \pm 0.01$ & $0.19 \pm 0.03$ \\
\hline \multicolumn{10}{|l|}{$\mathrm{CCP}$} \\
\hline ELI (HU) & $148.3 \pm 11.2$ & $354.4 \pm 13.7$ & $300.0 \pm 3.1$ & $31.7 \pm 0.7$ & $36.1 \pm 0.7$ & $26.4 \pm 0.5$ & $0.46 \pm 0.02$ & $0.39 \pm 0.01$ & $0.17 \pm 0.01$ \\
\hline HU1 (HU) & $83.6 \pm 16.4$ & $371.5 \pm 10.7$ & $310.1 \pm 28.9$ & $30.0 \pm 0.6$ & $35.6 \pm 0.6$ & $27.5 \pm 0.0$ & $0.46 \pm 0.1$ & $0.37 \pm 0.01$ & $0.17 \pm 0.01$ \\
\hline OYQ (UK) & $180.6 \pm 30.1$ & $405.7 \pm 19.5$ & $328.9 \pm 22.3$ & $30.2 \pm 1.1$ & $35.7 \pm 0.6$ & $26.9 \pm 1.5$ & $0.49 \pm 0.01$ & $0.36 \pm 0.02$ & $0.18 \pm 0.04$ \\
\hline \multicolumn{10}{|c|}{$\begin{array}{l}\text { Anova } p \text {-values by 'cultivar' and } p \text {-values of Pure Lines vs CCP and of Italian (IT) vs Hungarian (HU) Pure Lines orthogonal linear contrasts. Symbols '>' and '<' } \\
\text { indicate whether the average of the first term is higher or lower, respectively, than the average of the second term of the contrast }\end{array}$} \\
\hline Anova p by ‘cultivar’ & 0.367 & 0.169 & 0.465 & $3.3 e^{-11}$ & $1.8 \mathrm{e}^{-15}$ & 0.010 & $5.7 e^{-9}$ & $1.4 \mathrm{e}^{-8}$ & 0.001 \\
\hline Old vs Modern & ns. & ns. & - & $7.7 e^{-10}(>)$ & $1.6 \mathrm{e}^{-14}(>)$ & - & $5.4 \mathrm{e}^{-5}(<)$ & $1.6 \mathrm{e}^{-8}(<)$ & - \\
\hline Pure Lines vs CCP & ns. & ns. & ns. & $4.2 \mathrm{e}^{-10}(>)$ & $1.1 \mathrm{e}^{-6}(>)$ & $0.004(>)$ & $1.1 \mathrm{e}^{-5}(>)$ & $3.8 \mathrm{e}^{-7}(>)$ & $0.001(>)$ \\
\hline IT vs HU Pure Lines & ns. & ns. & ns. & $5.1 \mathrm{e}^{-7}(<)$ & $2.8 \mathrm{e}^{-11}(<)$ & $0.010(<)$ & 0.192 & 0.842 & $0.003(>)$ \\
\hline
\end{tabular}

MOC = Mix of Old Cultivars; BLR = Bolero; MMC = Mix of Modern Cultivars; EMS = Mv Emese; ELI = Elite CCP; HU1 = Hungarian CCP 1; OYQ = Orgainc Yield-Quality CCP; IT = Italy; $\mathrm{HU}=$ Hungary; UK= United Kingdom.

$\left({ }^{*}\right)$ ANOVA run on arcsin-transformed values.

average of the other cultivars, respectively). The HI of the CCPs was lower than that of the pure lines by $14.4 \%, 12.8 \%$ and $30.4 \%$ in Year $1-3$, respectively (Table. 6).

\section{Discussion}

In this work, we observed the development and performance, in terms of weed suppression and yield, of cultivars of varying identity and level of genetic diversity grown with or without a Subterranean clover living mulch, in an organic rotation across three subsequent seasons. These seasons were climatically very different from one another, resulting in huge differences in wheat performance. In 2010/11, very low grain yield was mainly due to low ear density, consequent to poor establishment of a late-sown crop. In 2011/12, optimal ear density under favourable climatic conditions supported a good yield. Instead, in 2012/13, unusually high rainfall joint with extreme, erratic climatic events strongly reduced the yield performance of a well-established wheat crop.

Overall, morpho-phenological functional traits, such as canopy height and growth cycle partitioning, were clearly differentiated by cultivar and showed no plasticity as regards to the presence of the living mulch. Differences in traits among cultivars were reflected in cultivar performance in terms of weed suppression and yield, and allowed clustering the tested cultivars based on either the functional identity hypothesis-Italian vs. Hungarian and British cultivars, old vs. modern cultivars - or the functional diversity hypothesis - CCPs vs pure lines. On the other hand, the living mulch presence affected wheat growth and yield, weed biomass and weed abundance, but the magnitude of the effects mainly depended on Subterranean clover establishment and growth.

\subsection{Discerning functional identity and diversity effects on cultivars performance}

The analysis of morpho-phenological functional traits highlighted three distinctions between cultivar groups. First, the old Italian cultivars were constantly and considerably taller than all the other cultivars throughout the entire growing cycle. This recalls identity differences belonging to breeding history, since the components of MOC were released before the widespread use of dwarfing genes in wheat breeding (Milach and Federizzi, 2001).

Second, the Italian pure lines (BLR and MMC) clustered against the Hungarian commercial cultivar EMS and the CCPs. The latter group showed a prostrate habit and high tillering during the early growth stages in the context of a late growing cycle while, for the same set of traits, the first group showed an opposite pattern. This recalls identity differences belonging to the geographical origin and climatic adaptation of the two groups of cultivars. In fact, Mediterranean wheats are mainly bred to avoid late spring drought through an earlier growth cycle (Isidro et al., 2011), while British and Hungarian wheats reasonably have to withstand winter frost as a main limiting environmental factor and are advantaged for this by a longer foundation phase (Curtis et al., 2002).

Third, a finer traits distinction emerged between the CCPs and the Italian (BLR and MMC) or Hungarian (EMS) pure lines. The CCPs showed a longer interval between the onset of stem extension and the completion of ear extrusion, which can be interpreted as an indicator of increased yield potential (Slafer et al., 2005). In CCPs we also observed a significantly lower severity of leaf spot diseases. Improved disease tolerance and resistance is a commonly found evidence in genetically heterogeneous crop stands (Finckh, 2008; Zhu et al., 2000), although Döring et al. (2015) suggested that this diversity-driven resistance is not really effective on generalist diseases as $M$. graminicola. These results might reasonably be seen as an effect of genetic diversity. In fact, the contrast between the Hungarian pure line EMS, whose phenological cycle was close to the CCPs, and the Italian pure lines BLR and MMC did not follow a similar pattern.

\subsubsection{Effects of functional identity}

The first and second distinctions, linked with the functional identity hypothesis, showed partly similar cultivar effects on cropweed interactions and on yield and yield components. The old cultivars showed some advantage in weed suppression, e.g., in 2011/12 weed biomass at wheat flowering was lower in MOC than in the other cultivars, thanks to their high vigour and tall canopy throughout the growing cycle. These have been reported to be traits correlated to better weed suppression in several other works (Huel and Hucl, 1996; Olesen et al., 2004; Yenish and Young, 2004). However, in 2011/12 - an optimal growing season - MOC yielded significantly less than all the other cultivars, although it showed the maximum average kernel weight. This confirms that a tradeoff between highly competitive traits and yield potential is often found in wheat (Reynolds et al., 1994).

Old cultivars are frequently reported as good candidates to improve and stabilise yield in organic wheat, as they should ensure 

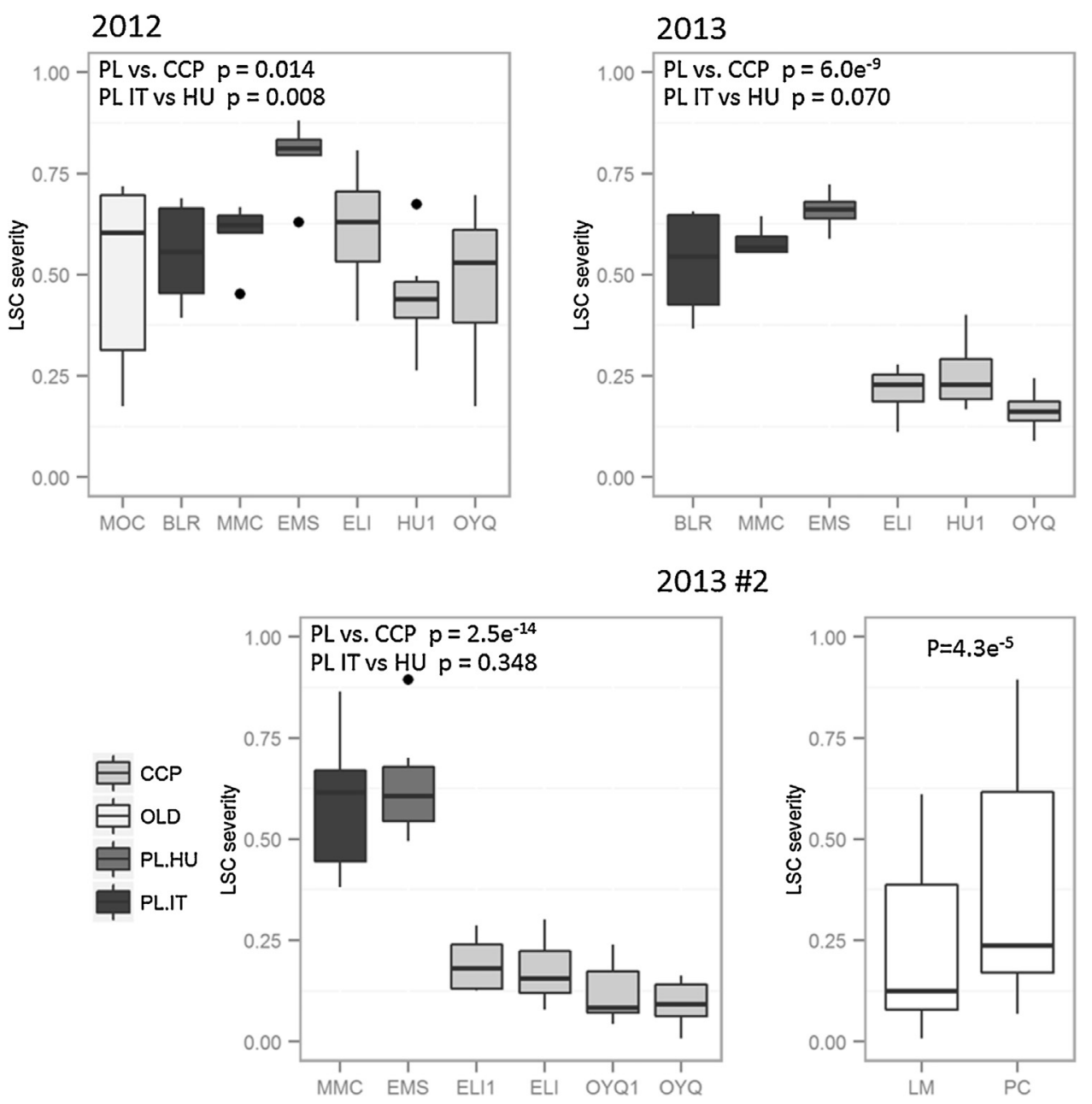

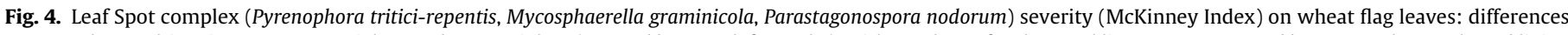

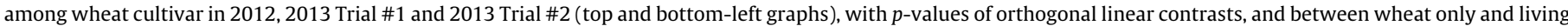
mulch systems in 2013 Trial \#2 (bottom-right graph), with anova $p$-value for 'system' factor.

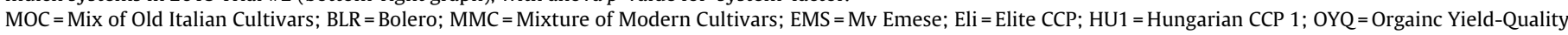
CCP. 'OLD vs MOD' = Old vs. Modern cultivars; 'PL vs CCP' = Pure Lines vs CCP; 'PL IT vs HU' = Pure Lines Italian vs Hungarian Cultivars.

better performance in stressful, limiting conditions (Stagnari et al., 2013). As far as yield is concerned, our results are more in line with works showing that, under limiting environmental conditions, modern cultivars can achieve better performances than old ones, especially when, as in organic farming, $\mathrm{N}$ commonly is a limiting factor (Guarda et al., 2004). However, this does not mean that we should reject the use old cultivars as a strategy to improve wheat performance. First, there are environments where weed pressure is a limiting factor that old cultivars can efficiently cope with thanks to both their taller canopy and the higher weight of their seeds, which can generate plants with higher early vigour and improved ability to capture environmental resources (Stougaard and Xue, 2004). Second, our results on old cultivars are limited to a mixture of four cultivars, which cannot be considered as representative of the full genotypic and phenotypic variation existing in old wheat germplasm, which is expected to be higher than among modern, post-Green Revolution cultivars (Bonnin et al., 2014). On this subject, some authors also pointed out important genetic erosion, as a result of agricultural modernisation (Van de Wouw et al., 2010). This is particularly important for landraces - i.e., the cultivars cultivated before the onset of early formal breeding programmes -, which are an essential reservoir of useful alleles for future breeding (Newton et al., 2010).
Concerning the group based on cultivar geographical origin, the outcome is a general advantage of the Italian over Hungarian and British cultivars as far as weed suppressive ability is concerned. The earlier growth cycle and the erect growth habit of Italian cultivars determined a higher biomass production in the early growth stages, which, in 2012/13, turned in a lower weed biomass at the onset of wheat stem extension, consistently with the hypothesis that early vigour is a key trait for weed suppressive ability (Olesen et al., 2004). The advantage of Italian cultivars over Hungarian modern cultivar and CCPs and British CCP was also shown by grain yield data in 2012/13. Although in this study genetic identity and withincrop heterogeneity cannot be fully separated, it is plausible that these differences in yield are due to the better climatic adaptation to local conditions of Italian cultivars. However, this was partly an accidental result. The extreme weather conditions occurred in midMay 2013, causing lodging of a crop already weakened by eyespot infection, hit the Hungarian and British cultivars in correspondence of the end of flowering, while the Italian cultivars had already completed grain formation. As a consequence, the latter had a higher harvest index, suggesting that lower yield of Hungarian and British cultivars was due to interference with kernel setting, rather than a lower yield potential, as confirmed by the number of spikelets ear $^{-1}$. 

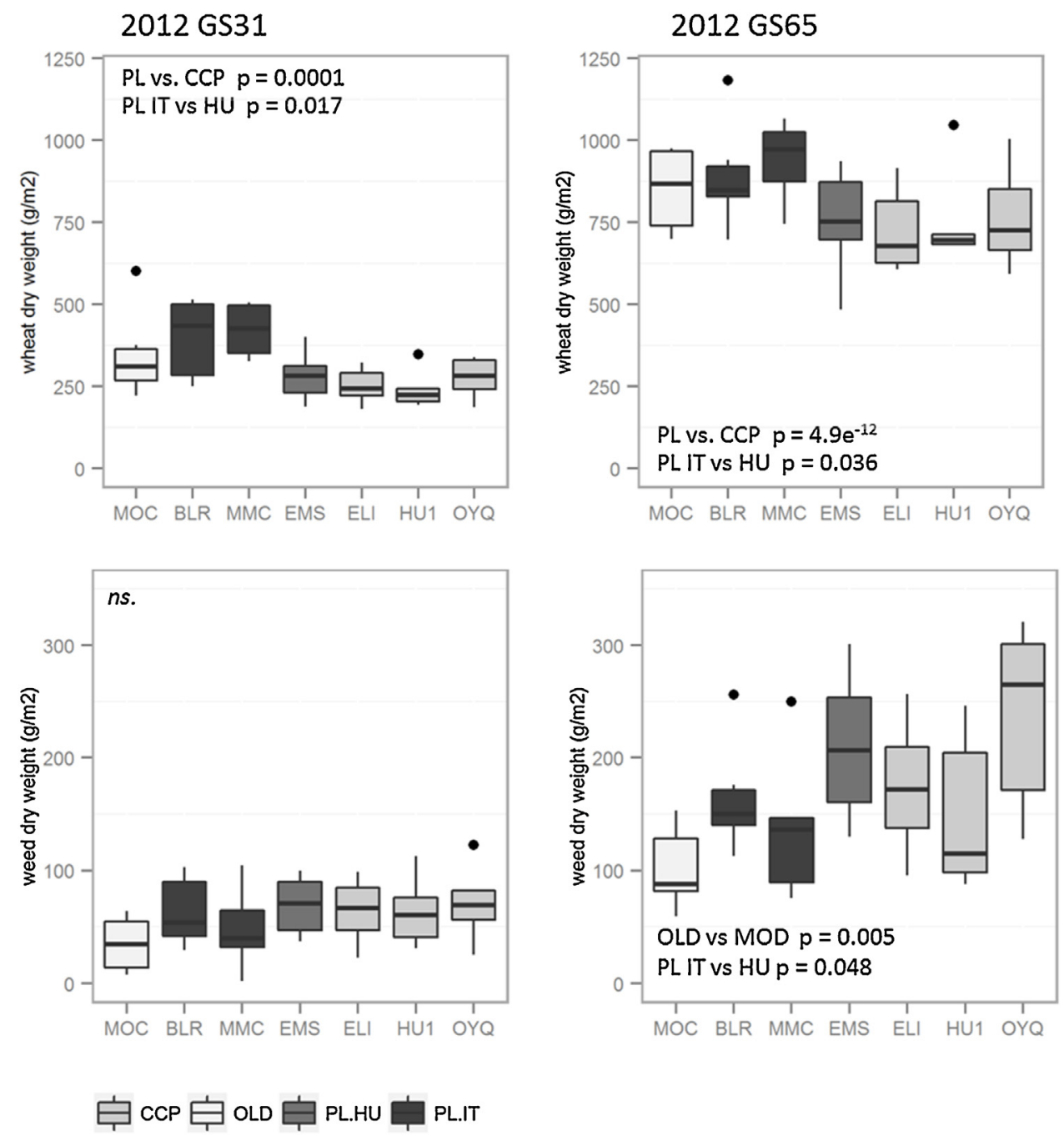

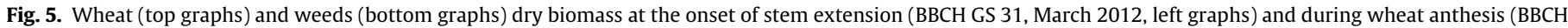
GS 65, right graphs): comparison among wheat cultivars in the 2011/12 crop season. $p$-values of orthogonal linear contrasts are indicated.

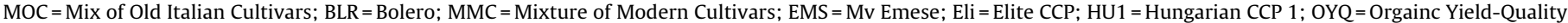
CCP. 'OLD vs MOD' = Old vs. Modern cultivars; 'PL vs CCP' = Pure Lines vs CCP; 'PL IT vs HU' = Pure Lines Italian vs Hungarian Cultivars.

Matching of cultivar growing cycle with local climatic pattern is crucial in ensuring a good performance in terms of weed suppression and wheat grain yield through optimal use of environmental resources and resistance to, or avoidance of the main stressors. We showed a trend of higher yield and better weed suppression obtained by Italian vs Hungarian and British cultivars across the three years of Trial \#1. However, since this advantage partly resulted from avoidance of a transient, extreme event occurring in one year, its predictive value for higher stability linked to explicit stress-tolerance mechanisms is limited. As a matter of fact, stressavoidance mechanisms do not protect the crop from the impact of unexpected, transient events, which may seriously reduce grain number, unless stress-tolerance mechanisms protect reproductive development (Dolferus et al., 2011).

\subsubsection{Effects of functional diversity}

Effects of morpho-phenological differences between CCPs and pure lines were confounded with identity effects mediated by geographical origin, particularly the mismatch between their growth cycle and local climate, but were consistent with results on yield and yield components. First, CCPs yielded slightly but significantly less than pure lines, including the Hungarian one, in 2011/12, an optimal growing season. Yield component analysis provided more informative results. Despite the confounding of identity and diversity in our experimental design, yield component analysis provided some insights on diversity and identity effects which are consistent with other observations and with literature. CCPs had a lower Harvest Index than the pure lines in all the three years of trials, revealing the existence of more competitive traits within the population. Moreover, homogeneous cultivars, especially the Hungarian EMS, had a high kernel weight while the CCPs had a lower kernel weight in all the three years. This suggests that CCPs, as a result of their evolutionary process, developed a yield formation strategy which maximises the number of kernels ear ${ }^{-1}$. This is consistent with the finding that CCPs had a longer phenological interval between BBCH GS 31 and 59. There is evidence that kernel number ear ${ }^{-1}$ is positively associated with duration of the phase from the onset of stem extension to ear extrusion and anthesis (Garcia et al., 2011; Sadras and Lawson, 2011; Whitechurch et al., 2007), which in our trials was found to be constantly longer in the CCPs than in the other cultivars. Therefore, we cannot exclude that these differences are the result of evolutionary processes mediated by offspring abundance, i.e., kernel number ear ${ }^{-1}$. This seemed to have been detrimental to kernels weight, as kernels development in a longer growth cycle is clearly exposed to late-spring drought. 

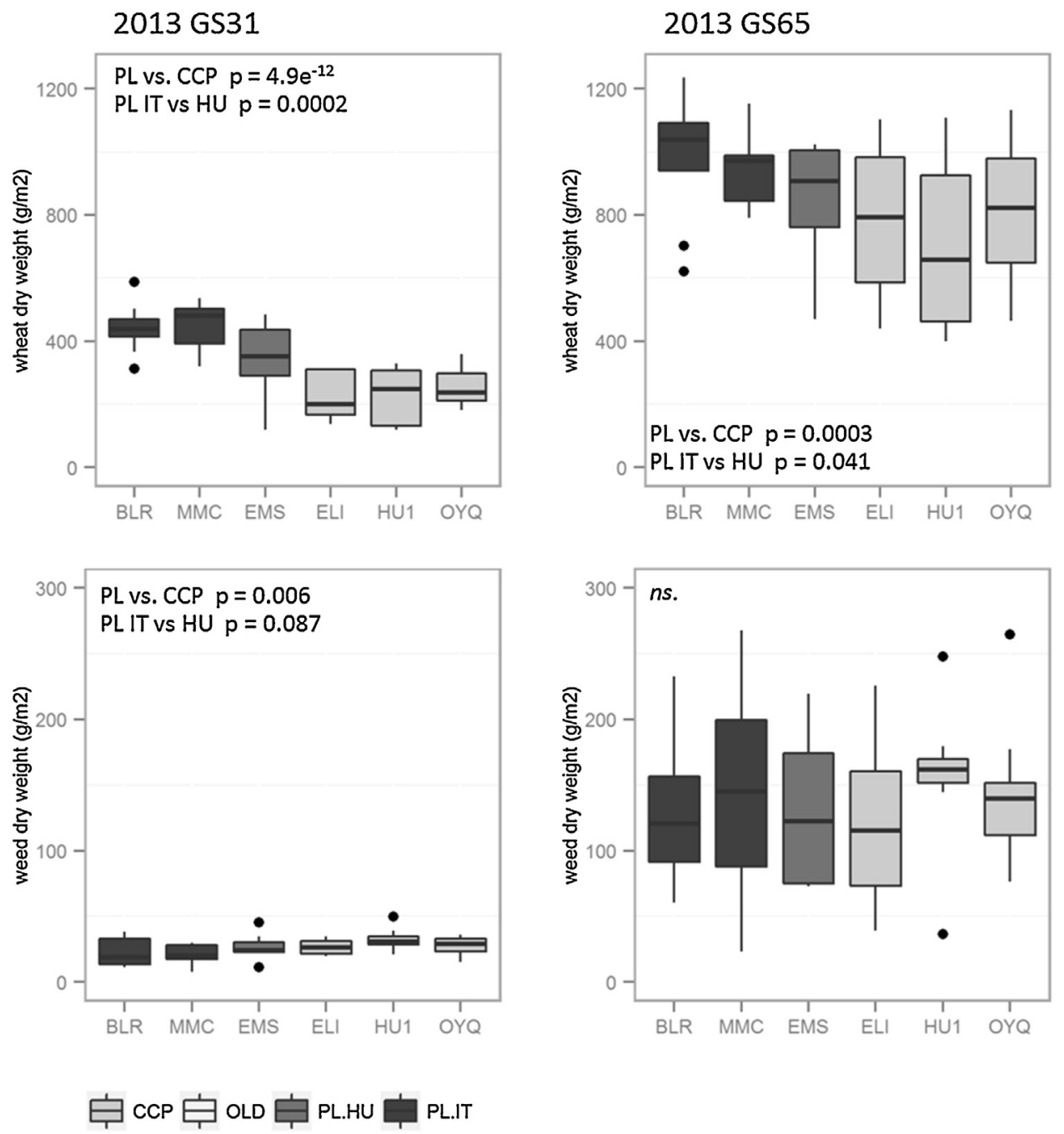

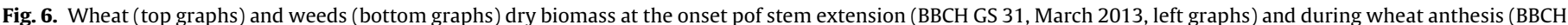
GS 65, 13 May 2013, right graphs): comparison among wheat cultivars in the 2012/13 crop season, Trial \#1. p-values of orthogonal linear contrasts are indicated.

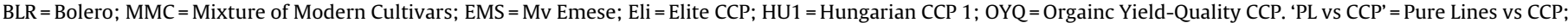
'PL IT vs HU' = Pure Lines Italian vs Hungarian Cultivars.

Deployment of genetic diversity in crops relies on the hypothesis that the co-presence of different traits, rather than a given architecture of traits, is more likely to stabilise yields in limited, unpredictable environments, as demonstrated by Ceccarelli et al. (1991). According to these authors, stabilisation would be the result of within cultivar buffering mechanisms, especially in self-pollinating winter cereals where heterozygosis-based individual buffering is insignificant. The co-presence of different response traits (sensu Hooper et al., 2002) would thus stabilise yields when faced with unpredictable variation, as frequently demonstrated in cultivar mixtures in the presence of diseases (Cox et al., 2004; Kiær et al., 2009). In evolutionary breeding, yield (Phillips and Wolfe, 2005; Suneson, 1956) and disease resistance (Goldringer et al., 1998) are also expected to progressively increase. However, these advantages tend to be counter-balanced by a gradual reversal to wild-type alleles (Knapp et al., 2013). In fact, it is possible that in optimal growing conditions, as in 2011/12, homogeneous crop stands suffered less intraspecific competition than heterogeneous crop stands. Reversal to wild-type alleles may indeed translate into a progressive shift towards the prevalence of more competitive genotypes, e.g., taller plants, in which a trade-off with yield can emerge.
As for weed suppression, two possible diversity effects can be expected in the CCPs. First, morphology variation and interspecific neighbouring relationship can favour interspecific competitive equivalence and weed species equitability (Fridley and Grime, 2010). At a first glance, this seems in contrast with the objective of reducing weed abundance. Second, progressive height increase would favour competition against weeds, as suggested by Knapp et al. (2013). However, no significant advantages or disadvantages of the CCPs against the pure lines were found in any of our trials.

As for yield, our results show that the CCPs have a markedly lower kernel weight, but not a consistently lower yield than the tested modern cultivars. The CCPs seem therefore to have developed a yield formation strategy characterised by a tendency to increase kernel number ear ${ }^{-1}$ through a longer construction phase, which was consistently longer than the modern cultivars indeed. The thorough work of Slafer et al. (2014) on wheat yield components identified kernel number $\mathrm{m}^{-2}$ as a 'coarse regulator' and kernel weight as a 'fine regulator' of yield. Kernel number $\mathrm{m}^{-2}$ is the product of ear density, which was not differentiated by cultivar, and kernel number ear $^{-1}$. Therefore, we can conclude that functional diversity confers the CCPs a high yield potential, provided that their functional identity, in terms of matching their growing 

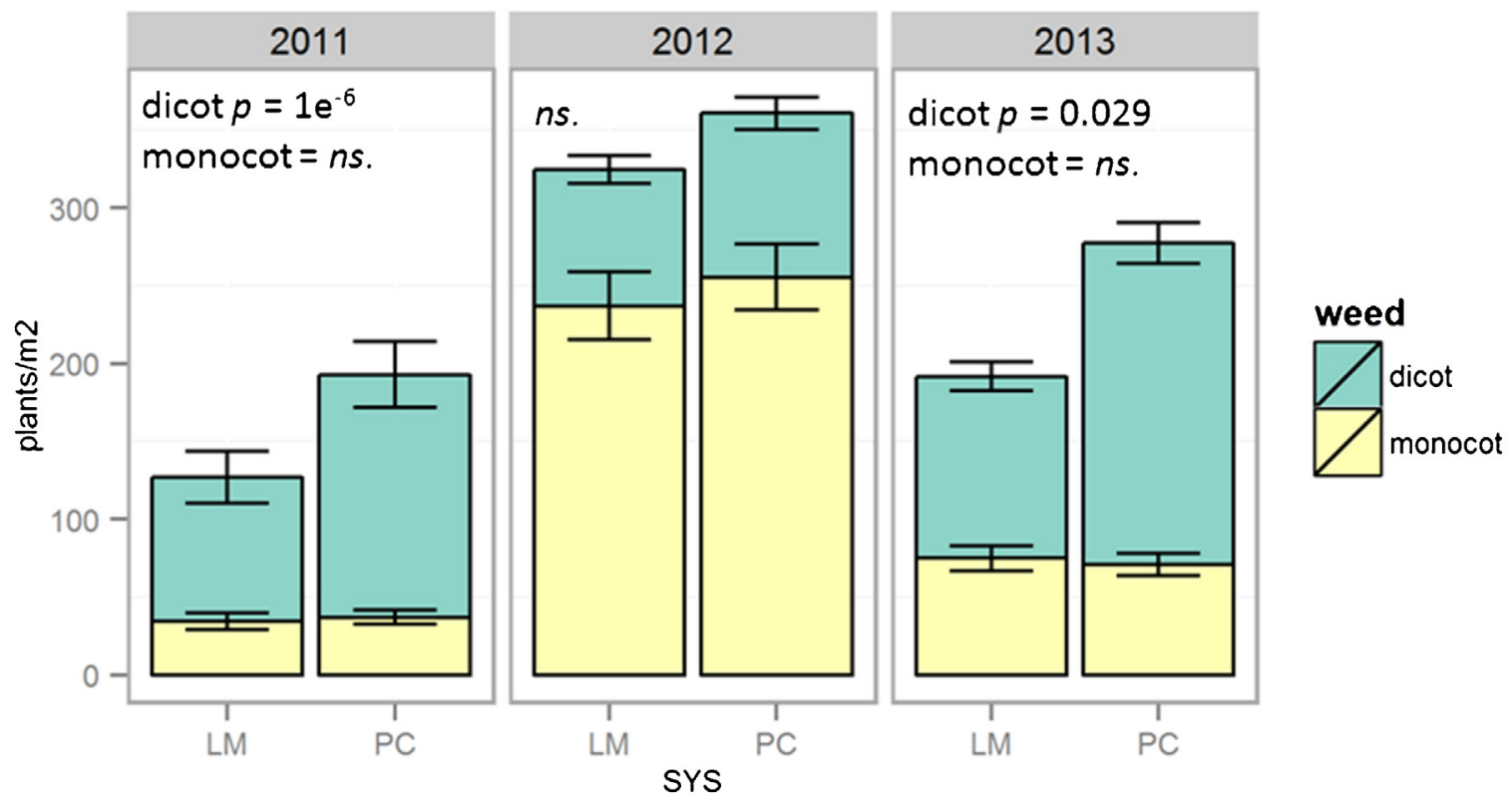

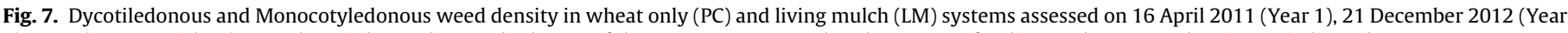
2), 2013 (Year 3, Trial \#1). Error bars indicate the standard error of the means. Anova $p$-values by 'system' for dicot and monocot density are indicated. 'LM' = Wheat with Living Mulch; 'PC' = Wheat Only.

cycle with local climate, allows them to avoid stresses interfering with optimal grain formation and filling.

\subsection{Understanding the effects of living mulch}

The living mulch affected crop performance independently of cultivars effect, unlike observed by e.g., Hiltbrunner and Liedgens (2008). This may be linked to the concurrent sowing of our living mulch and wheat, unlike the systems studied in Central and Western Europe. In fact, in these latter, the cereal is often sown into an already established clover stand (see e.g., Hiltbrunner et al., 2007a, 2007b; Thorsted et al., 2006) and has reasonably to face a stronger competition from the legume during the earliest stages. Hence, probably, the stronger performance differences among different wheat cultivars in these systems.

The living mulch had unstable effects, partly linked with the variable establishment and biomass accumulation of subterranean clover, which was intermediate in 2010/11, low in 2011/12 probably due to a cold and dry winter, and moderately (in Trial \#1) or extremely (in Trial \#2) high in 2012/13, thanks to a particularly mild and rainy winter. Overall, the occurrence of significant effects of the living mulch depended on a good establishment and growth of clover. These effects were (i) a suppression of wheat growth and grain yield, (ii) a suppression of weed biomass and (iii) a reduction of dicotyledonous, but not of monocotyledonous weed abundance. A further interesting effect of living mulch was the reduced severity of leaf spot diseases in Trial \#2 in 2012/13, suggesting that a thick clover layer can hamper the vertical dispersion of M. graminicola pycnidiospores (Bannon and Cooke, 1998).

Suppression of wheat growth and yield and suppression of weed biomass were not always concurrent, suggesting that such tradeoff is not unavoidable. Wheat growth and yield was reduced in 2010/11, a season with poor wheat establishment, and in Trial \#2 in 2012/13, when a suboptimal growth of wheat was observed. On the other hand, weed biomass was reduced by the living mulch in 2012/13 both in Trial\#2, when wheat growth was also suppressed, and in Trial\#1, where wheat was not affected by clover competition. This suggests that if wheat has optimal establishment and development during the early vegetative stages, it can successfully withstand the competition of an optimally established clover stand.

The living mulch system tested in our trials has original features, compared to the currently adopted system design in studies on cereal-legume intercropping. Living mulches are often established before wheat sowing (Hiltbrunner and Liedgens, 2008; Hiltbrunner et al., 2007a, 2007b; Thorsted et al., 2006). This is frequent in experiments carried out in Central-Northern Europe, where the living mulch is mainly aimed at optimizing $\mathrm{N}$ use efficiency and weed reduction. In southern Europe, instead, concurrent sowing of cereal and an intercropped legume is more frequent, and has been adopted e.g., by Vasilakoglou et al. (2008), in a whole-harvest cereal-vetch crop, and by Tosti and Guiducci (2010), with the legume ploughed in before the cereal reached the reproductive phase.

It is known that use of companion crops maximizes resource use complementarity when component crops differ in growth duration so that the times of their maximum resource requirement do not overlap. It is known as well that when the two component crops are sown concurrently and their growth cycles mostly overlap, competition for resources is intense and that the relative performance of the component crops is unstable (Fukai and Midmore, 1993). In our trials, this instability was evident and strongly related with living mulch efficacy in reducing weeds and with wheat-living mulch competition. Optimal spatial separation between the two components can optimize weed suppression minimizing trade-offs with yield of the main crop. For example, Campiglia et al. (2014) found that sowing wheat and subterranean clover in $10 \mathrm{~cm}$-distant rows was the best compromise, also ensuring a successful clover re-establishment in the subsequent season, in climatic conditions similar to those of our experiments. Differential suppression of dicot vs. monocot weeds, similarly to what reported by Hiltbrunner et al. (2007a) with several clovers tested as living mulches in wheat, has also to be carefully taken into account since monocots weeds often are most aggressive against wheat.

Designing successful wheat-living mulch systems would be a strategic aim in stockless cropping system, where legume presence in rotation is generally low. In organic and low-input conditions, such systems generally suffer from unbalanced nitrogen cycling 

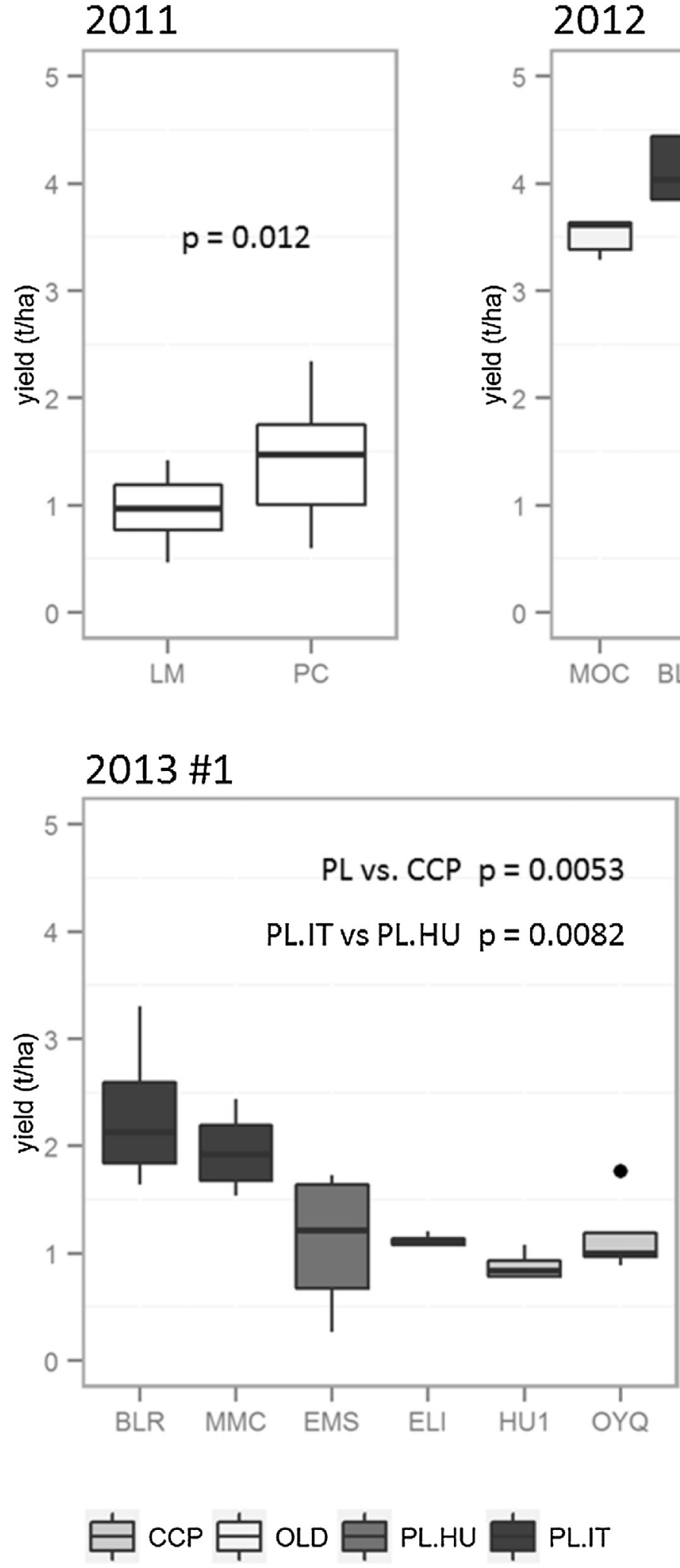

2012

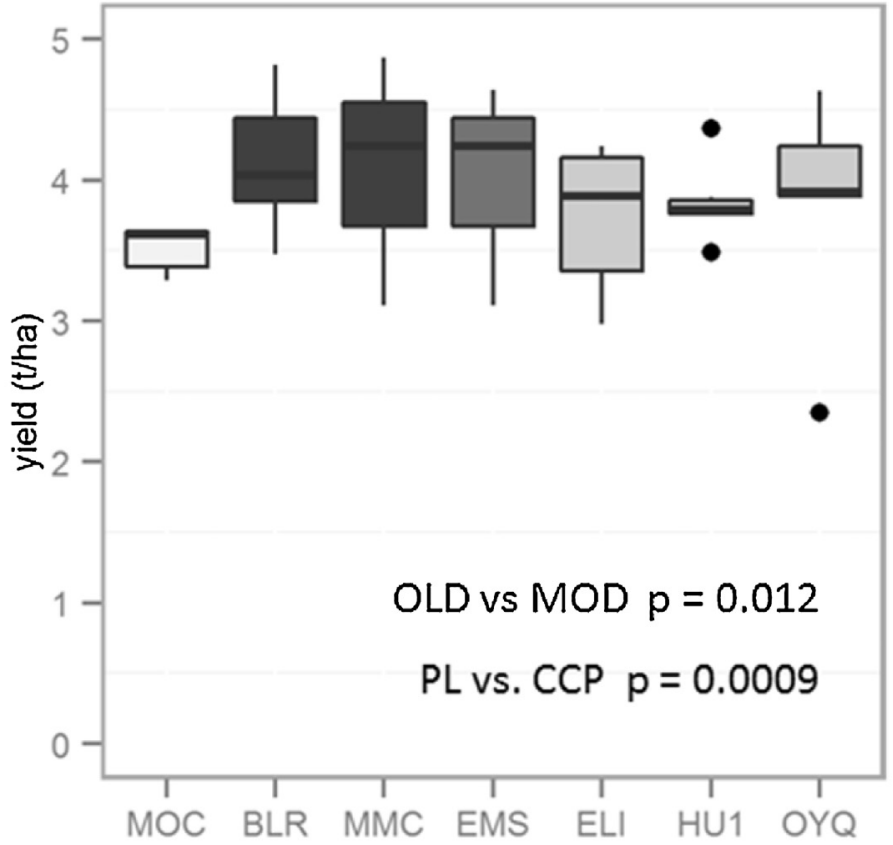

$2013 \# 2$

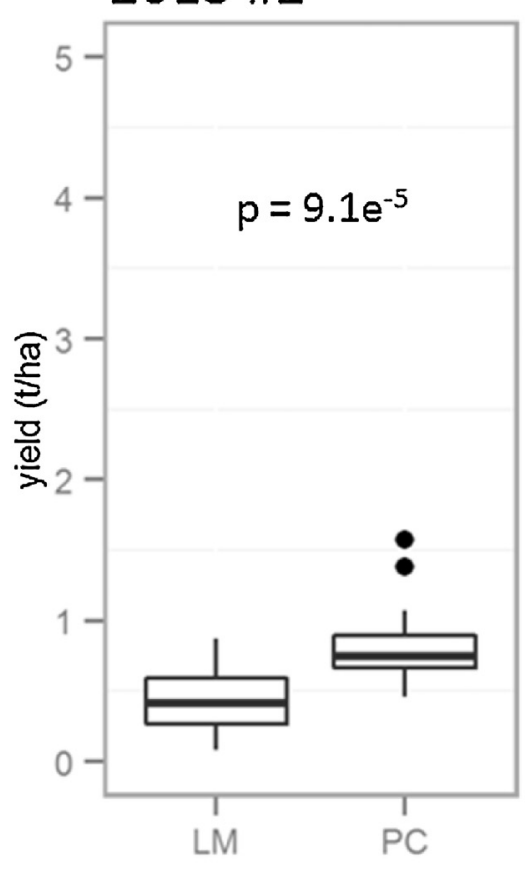

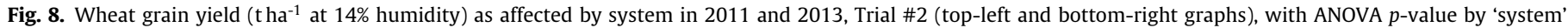
indicated, and by cultivar in 2012 and 2013, trial \#1 (top-right and bottom-left graphs), with p-values of sognofocant orthogonal linear contrasts.

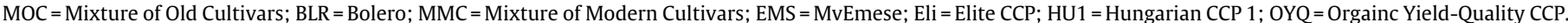
'OLD vs MOD' = Old vs. Modern cultivars; 'PL vs CCP' = Pure Lines vs CCP; 'PL IT vs HU' = Pure Lines Italian vs Hungarian Cultivars.

and high weed pressure due to the absence of livestock, manure and of a ley phase (Cormack, 2006; Rollet et al., 2006). Technical feasibility is however a bottleneck for adopting such strategies. Many papers have reported several tactics to enhance legumes functionality when intercropped with wheat as living mulches, including adjustment of sowing densities (Hiltbrunner et al., 2007b) and 
mechanical regulation of the living mulch (Thorsted et al., 2006). It is reasonable to think that the system adopted in our trials, with broadcast sowing of clover immediately before wheat sowing, is a feasible tactic. However, further efforts are necessary to understand (i) how to adjust the relative sowing densities of wheat and clover, (ii) the impact of weed harrowing on the clover stand, (iii) optimal living mulch species and cultivar choice.

\subsection{Future perspectives}

When interpreting our results in the light of functional identity, functional composition and functional diversity, this work suggests that future innovations in wheat systems require a clear hierarchy among these categories. Fit of functional identities into local macro-climatic conditions is a priority, especially for enhancing crop competitive ability against weeds and avoiding the main and most detrimental environmental stresses. Manipulation of functional composition, either by mixing cultivars or by including legume living mulches, and increase of functional genetic diversity are thought to be successful as long as the optimal functional identity is defined and respected.

These statements can have concrete implications. Spreading CCPs in different climatic areas, to seek for evolutionary-driven improvement in crop performance, appears a weak strategy, at least if there is an interest in using these cultivars for production. It may be of interest, instead, to diffuse CCPs with high genetic diversity (e.g., high number of highly distinct parentals) in wide areas for breeding purposes or to constitute CCPs from a pool of parental germplasms adapted to a target macroclimatic area. In this way, farmers and breeders would be able to select for the most useful types and/or against the least useful, thus obtaining well-adapted cultivars or lines to reproduce and include in fine-tuned productive cropping systems. Overall, our results suggest that CCP and evolutionary breeding have potential to increase and stabilise yield, with no negative effects on crop competitiveness. A crucial question for future research would be defining a critical spatial scale to optimise CCPs fitness and evolutionary adaptation.

Living mulch inclusion seems to have separate implications from the increase of wheat genetic diversity in our concurrently sown wheat-living mulch system, suggesting that there could be a high freedom in combining the two crops and managing their competitive interactions. Nevertheless, finding trait combinations that enhance complementarity effects while minimising interspecific competition is a priority. Insofar as wheat cultivars showed no differential performance with the living mulch, our experiment did not explore cultivar effects within Subterranean clover or other living mulch candidate species, which is worth studying more in depth.

Moreover, crop management adaptation to a more complex system than wheat sole crop is a critical factor in a living mulch. We consider that, in our climate, concurrent sowing of wheat and clover can be the most feasible strategy. We know as well that this approach exposes the component crops to higher interspecific competition and instability. Research of optimal trait combinations is critical in this respect but, to be successful, it must be tailored to pedo-climatic conditions and farming systems at a very narrow scale.

In summary, the categorisation of planned agrobiodiversity and tested in this work, although in an experimental design where the categories of diversity were inherently confounded, was useful to (i) highlight the potential effects of crop functional identity, functional composition and functional diversity on crop performance and (ii) suggest how these categories could integrate with one another in wheat cropping systems design. Adopting this framework on other crop typologies, e.g., summer crops or open-pollinated crops, can help testing the identity vs diversity hypothesis even in experiments where diversity and identity are confounded, and would allow a more global perspective on sustainable cropping system design.

\section{Acknowledgements}

We wish to thank Giacomo Nardi for his precious assistance during field trials. This work has been carried out with the support of the EU-funded project SOLIBAM (Grant agreement no.FP7-KBBE245058) and of the ERA-NET Core Organic II Project TILMAN-ORG.

\section{References}

Bannon, F.J., Cooke, B.M., 1998. Studies on dispersal of Septoria tritici pycnidiospores in wheat-clover intercrops. Plant Pathol. 47, 49-56, http://dx. doi.org/10.1046/j.1365-3059.1998.00200.x.

Bàrberi, P., Mazzoncini, M., 2006. The MASCOT (Mediterranean Arable System Comparison Trial) long-term experiment (Pisa, Italy). In: Raupp, J., Pekrun, C. Oltmanns, M., Köpke, U. (Eds.), Long-term field experiments in organic farming. ISOFAR Scientific Series, Verlag, Berlin (DE), pp. 1-14.

Bonnin, I., Bonneuil, C., Goffaux, R., Montalent, P., Goldringer, I., 2014. Explaining the decrease in the genetic diversity of wheat in France over the 20th century. Agric. Ecosys. Env. 195, 183-192, http://dx.doi.org/10.1016/j.agee.2014.06.003.

Campiglia, E., Mancinelli, R., Radicetti, E., Baresel, J.P., 2014. Evaluating spatial arrangement for durum wheat (Triticum durum Desf.) and subclover (Trifolium subterraneum L.) intercropping systems. Field Crops Res. 169, 49-57, http://dx. doi.org/10.1016/j.fcr.2014.09.003.

Ceccarelli, S., 1996. Adaptation to low/high input cultivation. Euphytica 92, 203-214.

Ceccarelli, S., 1989. Wide adaptation: how wide? Euphytica 40, 197-205.

Ceccarelli, S., Acevedo, E., Grando, S., 1991. Breeding for yield stability in unpredictable environments: single traits, interaction between traits, and architecture of genotypes. Euphytica 56, 169-185.

Chen, Y., Zhang, F., Tang, L., Zheng, Y., Li, Y., Christie, P., Li, L., 2007. Wheat powdery mildew and foliar $\mathrm{N}$ concentrations as influenced by $N$ fertilization and belowground interactions with intercropped faba bean. Plant Soil 291, 1-13, http://dx.doi.org/10.1007/s11104-006-9161-9.

Cormack, W.K., 2006. Crop performance in a stockless arable organic rotation in eastern England. Biol. Agric. Hortic. 24, 1-20.

Costanzo, A., Bàrberi, P., 2014. Functional agrobiodiversity and agroecosystem services in sustainable wheat production: a review. Agron. Sustainable Dev. 34, 327-348, http://dx.doi.org/10.1007/s13593-013-0178-1.

Cox, C.M., Garret, K.A., Bowden, R.L., Fritz, A.K., Dendy, S.P., Heer, W.F., 2004. Cultivar mixtures for the simultaneous management of multiple diseases: $\tan$ spot and leaf rust of wheat. Phytopathology 94, 961-969, http://dx.doi.org/10. 1094/PHYTO.2004.94.9.961.

Curtis, B.C., Rajaram, S., Gómez-Macpherson, H. (Eds.), 2002. FAO Plant Production and Protection Series, Rome (IT), ISBN 92-5-104809-6.

Dai, J., Wiersma, J.J., Holen, D.L., 2012. Performance of hard red spring wheat cultivar mixtures. Agron. J. 104, 17-21, http://dx.doi.org/10.2134/agronj2011. 0123.

Dolferus, R., Ji, X., Richards, R.A., 2011. Abiotic stress and control of grain number in cereals. Plant Sci. 181, 331-341.

Döring, T.F., Annicchiarico, P., Clarke, S., Haigh, Z., Jones, H.E., Pearce, H., Snape, J., Zhang, J., Wolfe, M.S., 2015. Comparative analysis of performance and stability among composite cross populations, variety mixtures and pure lines of winter wheat in organic and conventional cropping systems. Field Crops Res. 183, 235-245, http://dx.doi.org/10.1016/j.fcr.2015.08.009.

Döring, T.F., Knapp, S., Kovacs, G., Murphy, K., Wolfe, M.S., 2011. Evolutionary plant breeding in cereals: into a new era. Sustainability 3, 1944-1971, http://dx.doi. org/10.3390/su3101944.

Finckh, M.R., 2008. Integration of breeding and technology into diversification strategies for disease control in modern agriculture. Eu. J. Plant Pathol. 121, 299-409, http://dx.doi.org/10.1007/s10658-008-9273-6.

Flath, K., Cooke, M., et al., 2006. Disease assessment. In: Donner, D., Osman, A. (Eds.), Handbook Cereal Variety Testing for Organic and Low Input Agriculture. COST860-SUSVAR

Foletto, B., 2008. European rules for registration of varieties on a national catalogue (and a recommended variety list) for cereals, In: Rey, F., Fontaine, L., Osman, A., van Waes, J. (eds.). Proceedings of the COST ACTION 860-SUSVAR and ECO-PB Workshop on Value for Cultivation and Use testing of organic cereal varieties. What are the key issues? 28th and 29th February 2008, Brussels Belgium. SUSVAR, 228 COST, ECO-PB, ITAB, Paris, France, pp. 9-10 (full proceedings available at www.eco-pb.org).

Fridley, J.D., Grime, J.P., 2010. Community and ecosystem effects of intraspecific genetic diversity in grassland microcosm of varying species diversity. Ecology 91, 2272-2283, http://dx.doi.org/10.1890/09-1240.1.

Fukai, S., Midmore, D.J., 1993. Adaptive research for intercropping: steps towards the transfer of intercrop research findings to farmers' fields. Field Crops Res. 34, 459-467, http://dx.doi.org/10.1016/0378-4290(93) 90126-8. 
Garcia, G.A., Serrago, R.A., Appendino, M.L., Lombardo, L.A., Vanzetti, L.S., Helguera, M., Miralles, D.J., 2011. Variability of duration of pre-anthesis phases as a strategy for increasing wheat grain yield. Field Crops Res. 124, 408-416.

Goldringer, I., Prouin, C., Rousset, M., Galic, N., Bonnin, I., 2006. Rapid differentiation of experimental populations of wheat for heading time in response to local climatic conditions. Ann. Bot. 98 (4), 805-817, http://dx.doi. org/10.1093/aob/mcl160.

Goldringer, I., Paillard, S., Enjalbert, J., David, J.L., Brabant, P., 1998. Divergent evolution of wheat populations conducted under recurrent selection and dynamic management. Agronomie 18, 413-425, http://dx.doi.org/10.1051/ agro:19980506.

Guarda, G., Padovan, S., Delogu, G., 2004. Grain yield, nitrogen-use efficiency and baking quality of old and modern Italian bread-wheat cultivars grown at different nitrogen levels. Eur. J. Agron. 21, 181-192, http://dx.doi.org/10.1016/ j.eja.2003.08.001.

Hartwig, N.L., Ammon, H.U., 2002. Cover crops and living mulches. Weed Sci. 50, 688-699, http://dx.doi.org/10.1614/0043-1745(2002)050[0688:AIACCA]2.0. $\mathrm{CO} ; 2$.

HGCA, 2008. Wheat growth guide, 2nd ed. Last Downloaded on 4 April 2014 from http://www.hgca.com/media/185687/g39-the-wheat-growth-guide.pdf.

Hiltbrunner, J., Liedgens, M., 2008. Performance of winter wheat varieties in white clover living mulch. Biol. Agric. Hortic. 26, 85-101, http://dx.doi.org/10.1080/ 01448765.2008.9755071.

Hiltbrunner, J., Jeanneret, P., Liedgens, M., Stamp, P., Streit, B., 2007a. Response of weed communities to legume living mulches in winter wheat. J. Agron. Crop Sci. 193, 93-102, http://dx.doi.org/10.1111/j.1439-037X.2007.00250.x.

Hiltbrunner, J., Streit, B., Liedgens, M., 2007b. Are seeding densities an opportunity to increase grain yield of winter wheat in a living mulch of white clover? Field Crops Res. 102, 163-171, http://dx.doi.org/10.1016/j.fcr.2007.03.009.

Hooper, D.U., Solan, M., Symstad, A., Díaz, S., Gessner, M.O., Buchmann, N., Degrange, V., Grime, P., Hulot, F., Mermillod-Blondin, F., Roy, J., Spehn, E., Van Peer, L., 2002. Species diversity, functional diversity and ecosystem functioning. In: Loreau, M., Naeem, S., Inchausti, P. (Eds.), Biodiversity and Ecosystem Functioning-Synthesis and Perspectives. Ed. Oxford University Press, Oxford, UK, ISBN 978-0-19-851571-5.

Huel, D.G., Hucl, P., 1996. Genotypic variation for competitive ability in spring wheat. Plant Breed. 115, 325-329, http://dx.doi.org/10.1111/j.1439-0523. 1996.tb00927.x.

Isidro, J., Álvaro, F., Royo, C., Villegas, D., Miralles, D.J., García Del Moral, L.F., 2011. Changes in duration of developmental phases of durum wheat caused by breeding in Spain and Italy during the 20th century and its impact on yield. Ann. Bot. 107, 1355-1366, http://dx.doi.org/10.1093/aob/mcr063.

Jones, H., Jarman, R.J., Austin, L., White, J., Cooke, R.J., 2003. The management of variety reference collections in distinctness, uniformity and stability testing of wheat. Euphytica 132, 175-184, http://dx.doi.org/10.1023/A:1024642828705.

Kiær, L.P., Skovgaaed, I.M., Østergård, H., 2012. Effects of inter-varietal diversity, biotic stresses and environmental productivity on grain yield of spring barley variety mixtures. Euphytica 185, 123-138, http://dx.doi.org/10.1007/s10681012-0640-1.

Kiær, L.P., Skovgaaed, I.M., Østergård, H., 2009. Grain yield increase in cereal variety mixtures: a meta-analysis of field trials. Field Crops Res. 114, 361-373, http://dx.doi.org/10.1016/j.fcr.2009.09.006.

Knapp, S., Snape, J., Döring, T.F., Wolfe, M.S., Griffiths, S., 2013. Genetic analysis of evolving winter wheat populations reveals reversion to wild type, in: Döring, T.F., Howlett, S., Winkler, L., Wolfe, M.S. (eds.), Proceedings of the International Symposium on Evolutionary Breeding in Cereals, Aston University Birmingham (UK), 21 January 2013. The Organic Research Centre, Hamstead Marshall, UK, p. 9 (full proceedings available at orgprints.org/22440/).

Mason, H.E., Spaner, D., 2006. Competitive ability of wheat in conventional and organic management systems: a review of the literature. Can. J. Plant Sci. 86, 333-343.

McKinney, H.H., 1923. Influence of soil temperature and moisture on infection of wheat seedlings by Helminthosporium sativum. J. Agric. Res. 26, 195-217.

Mengistu, N., Baenziger, P.S., Nelson, L.A., Eskridge, K.M., Klein, R.N., Baltensperger, D.D., Elmore, W., 2010. Grain yield performance and stability of cultivar blends vs component cultivars of hard winter wheat in Nebraska. Crop Sci. 50, 617-623, http://dx.doi.org/10.2135/cropsci2009.05.0280.

Meier, U. (Ed.), 2011. BBCH monograph., 2nd ed. Federal Biological Research Centre for Agriculture and Forestry, Zurich $(\mathrm{CH})$.

Milach, S.C.K., Federizzi, L.C., 2001. Dwarfing genes in plant improvement. Adv. Agron. 73, 35-63, http://dx.doi.org/10.1016/S0065-2113(01)73004-0.

Mundt, C.C., Brophy, L.S., Schmitt, M.S., 1995. Choosing crop cultivars and cultivar mixtures under low versus high disease pressure: a case study with wheat. Crop Prot. 14, 509-515.

Mundt, C.C., Hayes, P.M., Schon, C.C., 1994. Influence of barley variety mixtures on severity of scald and net blotch and on yield. Plant Pathol. 43, 356-361.

Newton, A.C., Begg, G.S., Swantson, J.S., 2009. Deployment of diversity for enhanced crop function. Ann. Appl. Biol. 154, 309-322, http://dx.doi.org/10. 1111/j.1744-7348.2008.00303.x.
Newton, A.C., Akar, T., Baresel, J.P., Bebeli, P.J., Bettencourt, E., Bladenopoulos, K.V., Czembor, J.H., Fasoula, D.A., Katsiotis, A., Koutis, K., Koutsika-Sotirou, M., Kovacs, G., Larsson, H., De Carvalho, M.A.A.P., Rubiales, D., Russel, J., Dos Santos, T.M.M., Vaz Patto, M.C., 2010. Cereal landraces for sustainable agriculture. Agron. Sustainable Dev. 30, 237-269, http://dx.doi.org/10.1051/agro/2009032.

Olesen, J.E., Hansen, P.K., Berntsen, J., Christensen, S., 2004. Simulation of above-ground suppression of competing species and competition tolerance in winter wheat varieties. Field Crops Res. 89, 263-280, http://dx.doi.org/10. 1016/j.fcr.2004.02.005.

Phillips, S.L., Wolfe, M.S., 2005. Evolutionary plant breeding for low input systems. J. Agric. Sci. 143, 245-254, http://dx.doi.org/10.1017/S0021859605005009.

$\mathrm{R}$ Development Core Team, 2011. A language and environment for statistical computing. R Foundation for Statistical Computing, Vienna, Austria, ISBN 3-900051-07-0 http://www.R-project.org/.

Ratnadass, A., Fernandes, P., Avelino, J., Habib, R., 2012. Plant species diversity for sustainable management of crop pests and diseases in agroecosystems: a review. Agron. Sustainable Dev. 32, 273-303, http://dx.doi.org/10.1007/ s13593-011-0022-4.

Reynolds, M.P., Acevedo, E., Sayre, K.D., Fischer, R.A., 1994. Yield potential in modern wheat varieties: its association with a less competitive ideotype. Field Crops Res. 37, 149-160.

Rhoné, B., Remoué, C., Galic, N., Goldringer, I., Bonnin, I., 2008. Insight into the genetic basis of climatic adaptation in experimentally evolving wheat populations. Mol. Ecol. 17, 930-943, http://dx.doi.org/10.1111/j.1365-294X. $2007.03619 x$.

Rollet, A.J., Sparkes, D.L., Wilson, P., 2006. The legacy of stockless organic conversion strategies. Ann. App. Biol. 150, 107-113.

Sadras, V.O., Lawson, C., 2011. Genetic gain in yield and associated changes in phenotype: trait plasticity and competitive ability of South Australian wheat varieties released between 1958 and 2007. Crop Pasture Sci. 62, 533-549.

Slafer, G.A., Savin, R., Sadras, V.O., 2014. Coarse and fine regulation of wheat yield components in response to genotype and environment. Field Crop Res. 157, 71-83.

Slafer, G.A., Araus, J.L., Royo, C., García del Moral, L.F., 2005. Promising eco-physiological traits for genetic improvement of cereal yields in Mediterranean environments. Ann. App. Biol. 146, 61-70, http://dx.doi.org/10. 1111/j.1744-7348.2005.04048.x.

Stagnari, F., Onofri, A., Codianni, P., Pisante, M., 2013. Durum wheat varieties in $\mathrm{N}$-deficient environments and organic farming: a comparison of yield, quality and stability performances. Plant Breed. 132, 266-275, http://dx.doi.org/10. $1111 /$ pbr.12044.

Stern, W.R., 1993. Nitrogen fixation and transfer in intercrop systems. Field Crops Res. 34, 335-356, http://dx.doi.org/10.1016/0378-4290(93)90121-3.

Stougaard, R.N., Xue, Q., 2004. Spring wheat seed size and seeding rate effects on yield loss due to wild oat (Avena fatua) interference. Weed Sci. 52, 133-141.

Stubbs, R.W., Prescott, J.M., Saari, E.E., Dubin, H.J. (Eds.), 1986. Centro Internacional de Mejoramiento de Maíz y Trigo (CIMMYT), México, D.F., México.

Suneson, C.A., 1956. An evolutionary plant breeding method. Agron. J. 48, 188-191 http://dx.doi.org/10.2134/agronj1956.00021962004800040012x.

Thorsted, M.D., Olesen, J.E., Weiner, J., 2006. Mechanical control of clover improves nitrogen supply and growth of wheat in winter wheat/white clover intercropping. Eur. J. Agron. 24, 149-155, http://dx.doi.org/10.1016/j.eja.2005. 07.004.

Tosti, G., Guiducci, M., 2010. Durum wheat-faba bean temporary intercropping: effects on nitrogen supply and wheat quality. Eur. J. Agron. 33, 157-165, http:// dx.doi.org/10.1016/j.eja.2010.05.001.

Van de Wouw, M., Van Hintum, T., Kik, C., Van Treuren, R., Visser, B., 2010. Genetic diversity trends in twentieth century crop cultivars: a meta-analysis. Theor. App. Genet. 120, 1241-1252.

Vasilakoglou, I., Dhima, K., Lithourgidis, A.S., Eleftherohorinos, I., 2008. Competitive ability of winter cereal-common vetch intercrops against sterile oat. Exp. Agric. 44, 509-520, http://dx.doi.org/10.1017/S0014479708006728.

Whitechurch, E.M., Slafer, G.A., Miralles, D.J., 2007. Variability in the duration of stem elongation in wheat and barley genotypes. J. Agron. Crop Sci. 193 $138-145$.

Willer, H., Lernoud, J. (Eds.), 2014. Statistics and Emerging Trends 2014. FiBL-IFOAM report, Revised version of February 2014.

Wolfe, M.S., Baresel, J., Desclaux, D., Goldringer, I., Hoad, S., Kovacs, G., Löschenberger, F., Miedaner, T., Østergård, H., Lammerts van Bueren, E., 2008. Developments in breeding cereals for organic agriculture. Euphytica 163 , 323-346, http://dx.doi.org/10.1007/s10681-008-9690-9.

Wolfe, M.S., 2000. Crop strength through diversity. Nature 406, 681-682.

Yenish, J.P., Young, F.L., 2004. Winter wheat competition against jointed goatgrass (Aegilops cylindrica) as influenced by wheat plant height, seeding rate, and seed size. Wed Sci. 52, 996-1001

Zhu, Y., Chen, H., Fan, J., Wang, Y., Li, Y., Chen, J., Fan, J., Yang, S., Hu, L., Leung, H., Mew, T.W., Teng, P.S., Wang, Z., Mundt, C.C., 2000. Genetic diversity and disease control in rice. Nature 406, 718-722, http://dx.doi.org/10.1038/35021046. 